ARTICLE

DOI: $10.1057 /$ s41599-017-0021-4

\title{
Google and advertising: digital capitalism in the context of Post-Fordism, the reification of language, and the rise of fake news
}

\author{
Rosie Graham ${ }^{1}$
}

\begin{abstract}
Google's dominance over the web allows it to dictate various norms and practices that regulate the state of contemporary capitalism online. The way in which Google operates as a company and generates revenue is often sidelined in academic discussions regarding the cultural implications of how its search engine functions. Almost $90 \%$ of Google's revenue is derived from advertising, despite Larry Page and Sergey Brin's original academic paper regarding Google in which they argue that advertising produces mixed motives that make it an unfeasible way to fund search engines. This article outlines how Google's model of advertising reflects and encourages wider changes in capitalism as it shifts from its twentieth-century Fordist incarnation to contemporary Post-Fordist arrangements of labour. In doing so, this article analyses Google's two main advertising systems, AdWords and AdSense, and proposes that these financial models have significant effects upon online discourse. In discussing AdWords, this article details some of the tensions between the local and the global that develop when tracing flows of information and capital, specifically highlighting Google's impact on the decline of online language diversity. In outlining AdSense, this article demonstrates how Google's hegemonic control prescribes which parts of the web can be monetised and which remain unprofitable. In particular, in drawing from existing studies, evidence is provided that Google's AdSense programme, along with Google's relationship with Facebook, incentivised the rise of fake news in the 2016 US presidential election. This work builds on existing scholarship to demonstrate that Google's economic influence has varied and far-reaching effects in a number of contexts and is relevant to scholars in a range of disciplines. As such, this article is intended as a discursive introduction to the topic and does not require specific disciplinary background knowledge. In doing so, this article does not attempt to provide the final word on Google's relationship to digital capitalism, but rather, demonstrate the profitability of a Post-Fordist perspective, in order to enable a wider engagement with the issues identified.
\end{abstract}

\footnotetext{
${ }^{1}$ The University of Exeter, Exeter, UK. Correspondence and requests for materials should be addressed to R.G. (email: rg284@exeter.ac.uk)
} 


\section{Introduction}

his article focuses on how Google generates revenue and the various significant ways in which this impacts upon the wider digital information ecology on the web. Search engines have been addressed from a wide range of academic perspectives including, but not limited to, computer science, law, politics, information retrieval, and new media studies. ${ }^{1}$ However, the role that Google's advertising business model plays within contemporary capitalism is rarely addressed directly. This topic is crucially important because it impacts a wide-range of phenomena that might otherwise be considered non-economic, such as general online language use, and the incentives underpinning a range of content, such as fake news. In order to situate these issues within broader trends in contemporary capitalism, this article draws on Post-Fordist theory, which is outlined below, placing it within a digital context. This perspective highlights the extensive influence that Google's revenue model has upon digital culture.

Alphabet, Google's holding company created in 2015, is one of the most valuable companies in the world. ${ }^{2}$ It has a market value of over $\$ 500$ billion and in 2016 generated a revenue of $\$ 77$ billion. Ask someone what Google does and they will likely reply that it is a search engine company. However, a more accurate description is that Google is an advertising company. $88.7 \%$ of Google's revenue comes from advertising (Alphabet, 2017, p 22); although, as will be outlined below, Google's modes of advertising deviate significantly from any existing forms of traditional advertising. The economic success of such a shift is producing dramatically widespread effects within many areas of society. This article addresses two in particular: the reification of online language and the rise of fake news. There are many other important impacts of Google's advertising programmes, however, focusing on these two issues demonstrates the broad scope on which such a narrow economic model operates.

Google has two main advertising ventures. The first of which is 'Google properties', the service for hosting advertisements built into its own products (its search engine and Gmail, for example) the most significant part of which is AdWords. The second is 'Google Network Members' properties', a brokerage service that runs advertisements on third-party websites, the most significant part of which is AdSense. ${ }^{3}$ This article outlines AdWords and AdSense separately, as they each have different impacts, and highlights one pertinent consequence of each, the reification of language and the rise of fake news, respectively. $71.3 \%$ of Google's revenues comes advertising on Google's own sites and is mainly derived from AdWords (Alphabet, 2017, p 23). AdWords is an auction process that Google operates to allocate paid results (referred to by Google as sponsored results) to search engine queries, which sit separately on top or to the side of unpaid result (referred to by Google as organic results, see Fig. 1). These sponsored AdWords results are visually delineated from the organic results produced by the PageRank algorithm and other factors. In addition to this programme, $17.4 \%$ of Google's overall revenue is derived from non-Google sites on which Google hosts third-party advertising content using its AdSense programme (Alphabet, 2017, p 24). AdSense is Google's method of linking third-party advertisements to relevant third-party content, such as blogs or news sites, and displaying advertisements alongside selected content in digital billboards. Although there are other companies that provide advertising for third parties, Google AdSense is by far the largest. It was reported in The New York Times that '[i]n the first quarter of 2016, 85 cents of every new dollar spent in online advertising will go to Google or Facebook' (Herrman, 2016). The second section of this article outlines how these two companies reinforce their joint dominance.
The remaining $11.3 \%$ of Alphabet's revenue represents the sales of apps and media content in the Google Play store as well as other smaller ventures such as certain Google branded hardware, for example sales of Google Chromebooks and Pixel smartphones. None of Alphabet's other activities 'meet the quantitative thresholds to qualify as reportable segments; therefore, the operating segments are combined and disclosed [...] as Other Bets' (Alphabet, 2017, p 21) These smaller subsidiaries, known as other bets 'Access, Calico, CapitalG, Nest, Verily, Waymo, and X,' and other initiatives (Alphabet, 2017, p 21) have a combined revenue of $\$ 809$ million, which is only $0.9 \%$ of Alphabet's total revenue, and have combined operating losses of over $\$ 3578$ million (Alphabet, 2017, p 74). These divisions focus on a range of projects from Calico and Verily's biomedical research into extending the human lifespan, Waymo's self-driving cars, and X's Google Glass augmented reality headset. Whilst these kinds of projects are covered more frequently in the popular press they do not contribute to Google's financial success.

In summary: Google generates almost all of Alphabet's revenue; almost all of Google's revenue is made from advertising; the majority of this advertising revenue comes from AdWords, i.e., sponsored links included in search engine results; finally, Google spends a great deal of its revenue on smaller ambitious ventures. This article draws from Post-Fordist theory to provide a historical and theoretical context for Google's place in contemporary digital capitalism. In doing so, the article demonstrates the ways in which the Internet and the web have played a major role in the changing flows of information, labour, and capital and outlines how at the heart of this change is Google: both the company and its products. The first section of this article focuses on AdWords, arguing that it constitutes a global linguistic market and typifies a number characteristics of Post-Fordist capitalism. This section also addresses how Google's financial model contributes to the decline of language diversity online by incentivising the use of more profitable languages over others. The second section of this article focuses on the ways in which AdSense shapes online discourse and dictates particular norms. In particular, this section draws out the reciprocal links between AdSense and Facebook and demonstrates how Google's mode of advertising facilitated the rise of fake news during the 2016 US presidential election. Before addressing these two topics, the following section establishes the framework of Post-Fordist theory, in order to contextualise Google's activities within the broader shifts of contemporary capitalism.

\section{The context of Post-Fordism and Google's attitude towards advertising}

Google's modes of advertising represent a sea-change from traditional twentieth-century advertising which, in turn, operates within a much larger and more general shift away from twentieth-century modes of capitalism. This article draws from a particular group of thinkers, a group of Italian Neo-Marxists, loosely connected to the 'workerism' (operaismo) movement during the 1960s and 1970s, in order to better contextualise contemporary digital capitalism. The work of these thinkers-Paolo Virno, Michael Hardt, Antonio Negri, and Maurizio Lazzarato are a few notable examples-has come to be known as Post-Fordist theory. ${ }^{4}$ This designation of Post-Fordist theory represents a number of different, although related, attitudes towards the way in which capitalism has changed since the second half of the twentieth-century, specifically in regard to the role of work. Post-Fordist theory traces the decline of the dominant kind of capitalism in the early twentieth-century, Fordism $^{5}$ while theorising and analysing the post-industrial 


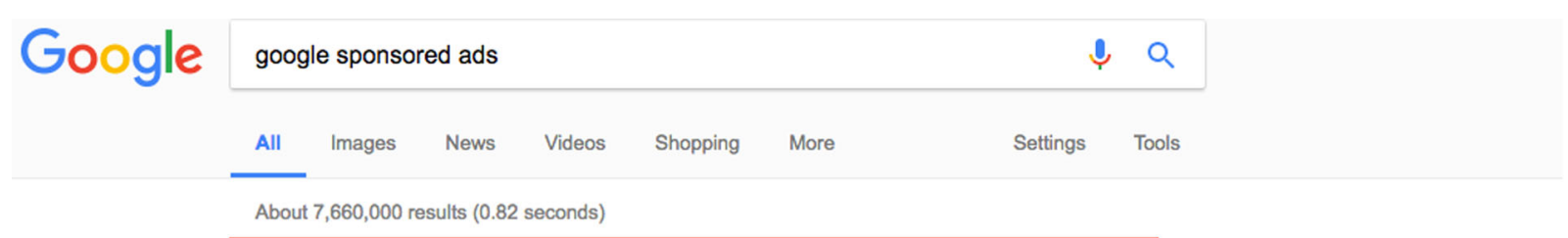

Advertising With Google - Use AdWords To Grow Your Business

Ad www.google.co.uk/AdWords -

Choose Keywords And Pay Per Click

Set Your Own Budget - Promote Your Website - Used by $1 \mathrm{~m}+$ Businesses - Free Help to Start

Services: Google AdWords, AdWords for Video, Google Display Network

Getting Started is Easy Costs

Start Now With AdWords Success Stories

Linkedln Sponsored Ads - $£ 50$ in Free Ad Credits - linkedin.com

Ad business.linkedin.com/sponsored-ads -

Boost Your Content Across Devices with Linkedln. Get £50 in Free Ad Credits Now!

Drive Brand Awareness - Generate Leads - 450M+ Member Reach - Promote Content

Types: Sponsored Content, Sponsored InMail, Dynamic Ads, Display Ads, Text Ads

Content Marketing · Linkedln Branding · Linkedln Sales Leads · Native Advertising

Google ads - WordStream.com

Ad] www.wordstream.com/GoogleAds v +1 857-362-8161

WordStream's Free Grader Can Help You Improve Your Account Today!

Google Sponsored Ads - AdvertisingWebService.co.uk

Ad google.advertisingwebservice.co.uk/

Get Your Website Listed Here, Fast. Risk Free Advertising - Try Now!

Google Ads - Create Online Ads for Your Business - Google

https://www.google.com/intl/en_uk/ads/.

Find out how Google Ads can help you get your business in front of your customers using display,

video, search and mobile advertising.

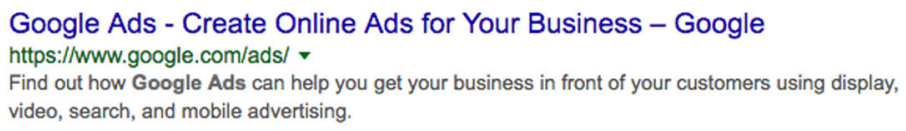

video, search, and mobile advertising.

\author{
Google PPC Online Advertising | Google AdWords - Google \\ https://adwords.google.com/ \\ Get your ad on Google today. Be seen by customers at the very moment that they're searching on \\ Google for the things you offer. And only pay when they click to ...
}

Google Sponsored Links: How to Get Your Ad in Google's Paid Links ...

www.wordstream.com/sponsored-links-google ?

Fig. 1 Google's sponsored results. The results in the red box are the sponsored results; the results outside of the red box are the 'organic' results organised by the PageRank algorithm and other factors. Screenshot taken by the author. This figure is licensed under a CC-BY Creative Commons Attribution 4.0 International License. Google and the Google logo are registered trademarks of Google Inc., used with permission

modes of capitalism that they describe as Post-Fordist. These models of Post-Fordist labour relations, which stress the importance of cognitive, flexible, and precarious labour, are key to understanding Google's influence on contemporary capitalism in a digital context. Various other thinkers outside of this Italian Neo-Marxist group have described the current mode of capitalism emphasising similar characteristics under a range of names: 'Empire' (Hardt and Negri, 2001), 'Late Capitalism' (Jameson, 1992), 'PostCapitalism' (Mason, 2016), 'Capitalist Realism' (Fisher, 2009), 'semiocapitalism' (Berardi, 2015), 'Cognitive Capitalism' (Boutang, 2012). Although these related approaches use different terminology, the various characteristics highlighted complement a description of contemporary capitalism as PostFordist.

The effects of Post-Fordism are numerous and many directly relate to Google's role in contemporary capitalism. To attempt to address all of these characteristic changes goes beyond the scope of a single article, however, it should be noted that Google's advertising ventures of AdWords and AdSense operate in concert with a range of other contemporary issues. These include: the increasingly precarious nature of employment; the dissolution of clear boundaries between work and free time, as well as between paid and unpaid work; the diminishing solidarity, rights, and freedoms of workers; the increasing time spent working, in each working day, as well as an increasing age of retirement; the homogenisation of different types of work through the use of information technologies; employing automation to replace workers; the changing nature of digital commodities that turn many product based industries into service ones. The list is only indicative, rather than exhaustive, aiming to provide a sense of Post-Fordism's extensive nature. An exaggerated example of a day that exemplifies Post-Fordist labour relations might be as follows: a woman catches an Uber to her timeshared office where she works as a digital brand consultant. Her work consists of managing Twitter likes and increasing Facebook engagement. She orders her lunch via an app, which is delivered by a part-time student working as a Deliveroo. She spends her evening watching Netflix, a subscription television service, as she does not have 
room to keep DVDs in her small Airbnb. That evening she spends an hour talking to a Chinese student over a language learning service, like italki, not to make money but in exchange for credits to be redeemed at a later date, once she finds the time to start learning Spanish. Not all work is like this, far from it; material labour is still a major part of contemporary work around the world. In addition, this example only highlights the visible changes that might seem to only effect a niche group of people. However, this article aims to show that Google's business draws everyone online into various immaterial labour arrangements with far reaching consequences, many of which are difficult to detect. There are numerous dimensions to such an arrangement and different people are implicated into Post-Fordist labour relations to different degrees. In focusing on how AdWords reifies language online and how AdSense incentivises fake news, this article demonstrates two examples in which all web users are impacted by Post-Fordist effects, even if their lives could not seem further from that of the example outlined above.

\section{AdWords: organic vs. sponsored results.}

'At least in terms of revenue generation, Google's core business isn't facilitating searches, it's selling advertising space-or rather, selling our attention to advertisers and managing both the price it charges for access to our attention and the relative visibility of those advertisements.' (Vaidhyanathan, 2012, p 26)

Vaidhyanathan's above quotation is useful because it draws our attention to Google's profitability as a company. That the majority of Google's revenue comes from the advertising through its search engine should be surprising, given that the original plan for Google's search engine was diametrically opposed to advertising. Despite the plans of the founders for Google to remain in the academic realm, Google generates revenue when users click on advertisements, not when users find successful answers to their queries. As Steven Levy describes, '[i]n their original academic paper about Google, [Larry] Page and [Sergey] Brin had devoted an appendix to the evils of conventional advertising' (2011, p 84). Their academic paper argued that their method, using the PageRank algorithm, was far more accurate than existing search engines that relied on advertising specifically because it did not bias results in order to make a profit. Their approach required that their search engine be 'transparent and in the academic realm' because, as the founders explain:

'advertising funded search engines will be inherently biased towards the advertisers and away from the needs of the consumers. [...]

Furthermore, advertising income often provides an incentive to provide poor quality search results. For example, we noticed a major search engine would not return a large airline's homepage when the airline's name was given as a query. It so happened that the airline had placed an expensive ad, linked to the query that was its name. A better search engine would not have required this ad, and possibly resulted in the loss of the revenue from the airline to the search engine. In general, it could be argued from the consumer point of view that the better the search engine is, the fewer advertisements will be needed for the consumer to find what they want. This, of course, erodes the advertising supported business model of the existing search engines.' (Brin and Page, 1998)

However, early on in their business, Google started using advertisements to fund their search engine. These advertisements, sponsored links, have always been kept separate from the organic links. In their paper, Brin and Page specifically took aim at search engines that mixed their results together so that users could not see which of the results had been paid for and which were freely chosen by the search engine. In this regard, Google have not gone back on their original statement; however, the problem remains: if a set of results is good enough, a user will never need to click on the sponsored link. In the original vision outlined by Brin and Page, advertisements are always an indication of failure, but today represent the overwhelming majority of Google's revenue. The following section outlines how this perspective of success vs. failure is deceptive and provides a different lens with which to describe the complex relationship between Google's search engine and advertising.

AdWords: the first global, real-time and multilingual linguistic market. This section provides a specific outline of how AdWords operates in order to demonstrate the close links between Google's search engine and advertising. In particular, this section draws on the work of Frederic Kaplan who argues that AdWords constitutes a form of 'linguistic capitalism' (2014, p 58), in the tradition of Post-Fordism; the conclusion of which is that Google's mode of advertising is having a widespread effect on all language usage on the web. Even if users are not explicitly altering the language they use online, anyone who uses the web communicates in a context where economic value alters every part of their linguistic landscape. Users may be completely unaware of this process of linguistic reification but still navigate an uneven digital space in which there are economic incentives that prioritise some words and ideas and deprioritise others. In addition, the economic value of different languages is not the same, and therefore, as discussed later, each language group is affected to a different extent.

AdWords is the auction system that provides advertising in the form of sponsored results that fill the top or side of a Google search result. An auction occurs every time a query is searched and balances the amount of money automatically bid by a company, against an automated quality score, given by Google. If low-quality scores are given or if there has not been an advertisement placed that is deemed relevant to the query, Google will not provide an advertisement. If a user clicks on one of these sponsored advertisements, the company being advertised pays Google; if not, no money is exchanged. Therefore, both Google and its business customers have strong economic incentives for the advertisements to succeed. A key aspect of AdWords is designing advertisements with specific kinds of search queries in mind. Kaplan explains that, '[f]irst, advertisers select a keyword-for instance 'vacation'-and define the maximum price they would be ready to pay if a user arrives on their site by clicking on the link of the ad' (2014, p 58). Keywords selected by advertisers are then used interchangeably with other similar words selected by Google. The advertiser must also select the 'product or service [they] wish to advertise' from a predetermined list, the language they wish to advertise in, and the geographical locations they wish to target with their advertising. Google has guidelines for prohibited AdWords content, ${ }^{6}$ which mostly relate to more general country specific laws. ${ }^{7}$ In addition, the process of having to choose from a preestablished list of products and services means that many taboo grey areas are condensed into more general subjects and thus implicitly censored. After this process is completed

'Google associates a quality score with the ad. This figure, ranging from 1 to 10 , evaluates the global 'quality' of the ad, which is computed through a complex combination of various factors, including the relevance of the text ad regarding the keyword, the average number of clicks on the ad, and the performance and quality of the linked website. This score measures how well the ad is working.' (2014, p 58) 


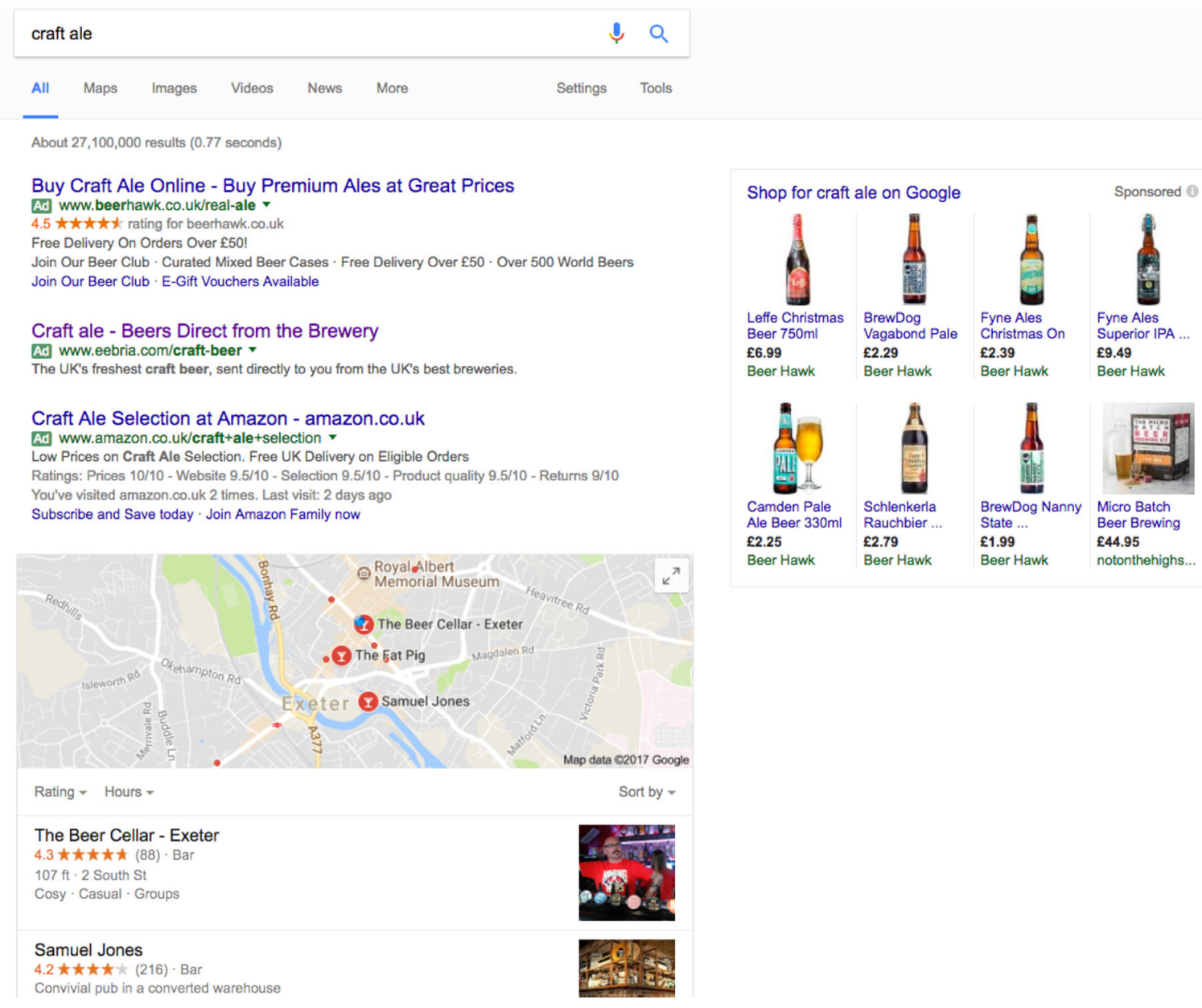

Fig. 2 AdWord results for 'craft ale'. The advertisement order lists the specialist and local sponsored results before Amazon's advertisement. Screenshot taken by the author. This figure is licensed under a CC-BY Creative Commons Attribution 4.0 International License. Google and the Google logo are registered trademarks of Google Inc., used with permission

This measure of 'quality' takes into account a judgement of the advertisement (clarity of expression), its relevance to the website it links to (an advertisement for swimming goggles should lead to a sports equipment shop rather than a public swimming pool), and the quality of the destination website (based on Google's usual metrics including the layout of keywords and the link score generated from other websites linking to that site). Whereas traditional advertising might aim to change someone's mind or introduce them to a new idea, AdWords advertisements are an attempt to reflect the existing perspective of an individual. AdWords advertisements, in aiming to be relevant, need to replicate the current outlook of a user, or successfully predict their context, in order to be given a high-quality score. Finally, the 'rank of an ad is calculated by multiplying the bid times the quality score' therefore an 'ad with a good score and medium bid can overcome a less efficient ad with a higher bid. Eventually, the price paid by the advertisers is not their maximum auction offer but a slightly lower price, one computed on a second-price auction model' (2014, p 59). This financial model means that small advertisers can compete with larger ones if they can offer a higher quality advert, as judged by Google. So, for example, in a search for 'craft ale' (see Fig. 2) Amazon might have set the highest bid for that phrase but it is listed underneath two smaller but more specialised craft beer sellers, with higher quality scores. This approach prevents companies with deeper pockets outbidding smaller but more relevant competitors.
An AdWords auction occurs every single time a user searches a query using Google's search engine. An estimate, based on Google's statement to search engine expert Danny Sullivan, that they handle at least ' 2 trillion searches per year' (Sullivan, 2016), means that at the lowest estimate, Google runs a staggering 63,000 linguistic auctions per second. Kaplan describes this process as:

'the first global, real-time and multilingual linguistic market. As a consequence, the fluctuation of the price of keywords indirectly reflects global linguistic movements. The value of some keywords like 'snowboarding' or 'bikini' varies seasonally. The increase and decrease of the word 'gold' is linked with the perceived state of financial crisis. Google makes a lot of money on some very competitive keywords like 'flowers,' 'hotels,' 'vacation' and 'love.' It also organises bids for buying the names of famous people ('Picasso,' 'Freud'). Bidding strategies vary. Anything that can be named can be associated with a bid.' (2014, p 59)

Google provides advertisers using AdWords with a tool that organises, suggests and estimates the cost of various words and phrases. Not only do the prices reflect real world events, but also, various companies can drive up the prices of words for their competitors. Such behaviour was raised in the 2007 court case 'Google, Inc. v. American Blind \& Wallpaper Factory, Inc.' John Battelle in The Search details how 
'in early 2003, American Blinds realised that while it owned the trademark on 'American Blinds,' it didn't own the market for it on Google's AdWords service. Competitors were snatching up the company's trademarks as AdWords terms (they did so by paying more for them, essentially), so that when customers typed 'American blinds' into Google they'd get advertisements for companies like JustBlinds. com and Select Blinds.' (Battelle, 2006, p 180)

The case of American Blinds vs. Google was described by commentators as a clear-cut trademark infringement that favoured American Blinds, however in a shock to many legal commentators, after 'almost 4 years of litigation' American Blinds finally dropped the suit in a "stunning victory for Google,' wrote Eric Goldman, an assistant professor at Santa Clara University School of Law' (in Auchard, 2007). Google has a track record for winning legal battles that establish digital norms ${ }^{8}$ and this case changed the conventional understanding of how legal definitions of ownership translate online. Google's legal defence outlined an aggressive position concerning the relationship between language and capital: old notions of linguistic ownership do not apply online. Not only are all words and phrases available to anyone, the auction winners are not even necessarily the highest bidder. Google's quality ranking system, when coupled with their dominance in the search engine market, means that they have become the gatekeeper of language ownership online. As language ownership is calculated and awarded anew through an auction every single time a search takes place, at least 63,000 times a second, no one can really claim ownership of language: words and their relation to entities are constantly in flux under Google's watchful eyes.

Because AdWords effects all words, not just copyrighted ones, we have a situation in which all words and ideas online are becoming commodities. The advertising model of AdWords, therefore, encourages companies into an association with language whereby a company does not connect their product with a specific slogan but to an unlimited range of words, at various times in specified locations. Many scholars have linked this expansion to the concept of the 'long tail', originally popularised by Chris Anderson, ${ }^{9}$ as Levy explains

'[s]ince Google searches were often unique, with esoteric keywords, there was a possibility to sell ads for categories that otherwise never would have justified placement. On the Internet it was possible to make serious money by catering to the 'long tail' of businesses that could not buy their way into mass media.' (2011, p 85)

Because of this phenomenon, and in conjunction with the auction aspect of AdWords that means that uncommon words are very cheap to bid on, all words in all languages can theoretically become profitable. There is an incentive to increase the prices of popular words but also to spread the reach of a campaign to niche words that might not seem in any way commodifiable but would have a low market value. Because advertisers are only charged when a user clicks on their advert there is no cost or disadvantage to placing bids on uncommon or unlikely words. This structural logic places clear incentives on advertisers to increase the scope of their chosen words and encourages a kind of linguistic land grab. Such an expansion then has an effect on all language used online, not just trademarks or particular phrases associated with companies or products. In shifting which words and phrases become discoverable through a search engine, and which are concealed, as well as how certain language becomes received in various contexts, economics comes to structure an increasing percentage of online linguistic communication. Kaplan argues that

'[e]ven if Google's autocompletion may not be explicitly biased toward more economically valuable expressions, it nevertheless tends to transform natural language into more regular, economically exploitable linguistic subsets.' (2014, p 60)

When born-digital content, for example online news, is written with search engine visibility in mind it is, in effect, automatically tailored towards advertising; advertisers and content creators both want to strengthen their association to the kinds of words and phrases used in search engine queries. In addition, as online content is increasingly dependent on third-party advertising, a topic that is discussed in second section of this article, these two activities-bidding on search terms and writing online content that is discoverable through search engines-become enmeshed and mutually standardise the kinds of linguistic patterns on the web.

Google's institutionalisation, data-collection and advertising. This standardisation across languages is also enhanced by Google's institutionalisation of the AdWords programme. Not only do companies that advertise through AdWords have access to numbers of tools and analytics, but this work is often outsourced to professional AdWords companies. ${ }^{10}$ Google runs a certification programme which provides training, study materials and holds exams for individuals to become accredited. To keep their status as an accredited AdWords professional, individuals need to pass two of Google's AdWords exams every year. In order for an advertising company to work as a 'Google Partner', they need to employ at least two members of staff who are currently accredited as AdWords professionals. The AdWords accreditation has even been added as a component of many Business Masters (MBA) degrees. ${ }^{11}$ Google also supplies funding to those institutions awarding MBAs through their 'Google Online Marketing Challenge $^{12}$ which strengthens links between universities, professors, and students with Google AdWords and in turn strengthens Google's hegemony.

Through Google's various projects, the company has an enormous collection of data, which, when combined with their methods of tracking users' behaviour on the web ensure that Google's advertising efforts are as effective as possible. As Ken Auletta describes:

'It was Google's ambition, Schmidt and Page and Brin liked to say, to provide an answer to the adman's legendary line 'I know half of my advertising works, I just don't know which half.' To help them sort through the digital clicks, Google and other new media companies relied on what are called cookies, software files that reside on a user's browser and keep track of their activities online: search questions asked, Web pages visited, time spent on each Web page, advertisements clicked on, items purchased [...] Although the cookie doesn't identify the user by name or address, it does assemble data advertisers crave and couldn't get from traditional media companies.' (2011, p 7)

Cookies and measurements of user interactions with search results allow Google to capture latent information that is used to further personalise advertising.

Describing Google as an advertising company (rather than a search engine that also advertises) refigures their search engine simply as a way of capturing economically useful information through mutual consent. Commentators have noted how many of Alphabet's projects that might seem very separate from Google's core business of Search, serve an important role in increasing advertising or data-collection opportunities. For example, Google Glass, an augmented reality headset released in 2013, does not immediately seem linked to the business of a search engine. However, Google was awarded a number of advertising-related patents that could be used with Google Glass. One of these 
patents, Pay-Per-Gaze, uses eye tracking to allow 'advertisers [to] be charged a fee based on whether a person looks directly at an ad in the real world, and the fee can change based on how long they interact with the ad' (Miller and Bilton, 2013). The patent also covers the measurement of pupil dilation so that the inferred emotional state information can be provided to an advertiser (perhaps for a premium fee) so that the advertiser can gauge the success of their advertising campaign' (from the patent 'Gaze Tracking System' (Neven, 2011) quoted in Truong, 2013). These kinds of advances add an economic perspective with which to reevaluate Google's mission statement: 'to organize the world's information and make it universally accessible and useful' (Google, 'About us'). ${ }^{13}$ Producing a patented system that monitors and records a person's gaze and pupil dilation is a way of making existing information 'useful' and provides a physiological metric with which to measure relevance. If Google Glass records that a person did not look at an advertisement for long or was not excited by it, they can change or replace that advertisement for something that sustains their gaze, widens their pupils and quickens their pulse. Other such examples can be seen in patents relating to other Alphabet ventures (the Other Bets highlighted in the introduction) such as Nest and Google Home. These patents range from 'Advertising Based on Environmental Conditions' (Heath, 2012) (coordinating a range of different sensors in the home and from mobile devices), to 'Coupling an Electronic Skin Tattoo to a Mobile Communication Device' (Alberth, 2013) (which consists of a microphone permanently embedded in a user's throat). Such developments allow Google to capture increasing amounts of data on and offline in order to increase the opportunities to commercialise existing behaviour.

The strategy of AdWords marks a departure from traditional advertising in a number of ways. As Levy argues, the AdWords policy

'reflected the different philosophy Google brought to advertising in general. Google ads were answers. They were solutions. 'Ideally we wanted people to have a 50 to 100 percent click rate,' says [Tim] Armstrong [Vice President of Ad Sales at Google].' (2011, p 112)

Aiming for a click rate above 50\% means that Google hoped for users to click on the sponsored advertisement link more often than the top algorithmically produced organic result. In doing so, Google wanted users to place their faith in the advertised links as representing more useful or relevant answers than the search results. The way in which the advertising is so embedded in the function of Google's search engine complicates an existing notion, borrowed from older media forms such as television or newspapers, that advertising revenue financially supports a medium but fundamentally stays separate to the content of that medium. This then raises the question, is AdWords really a form of advertising at all? To further interrogate this question we now turn to Raymond Williams' critical history of advertising 'Advertising: The Magic System' (1980).

AdWords in the context of 'The Magic System'. Williams' essay provides a history of advertising as a specifically contextual activity. To stress the historicity of advertising, Williams begins by dismissing a dominant conception that the history of advertising can be traced back to documents such as a 'three thousand year old papyrus from Thebes, offering a reward for a runaway slave' or he adds, tongue-in-cheek, 'some pleasant recollections from the Stone Age' (1980, p 170). Instead, advertising 'was developed to sell goods, in a particular kind of economy' (1980, $\mathrm{p}$ 183) and following its history from the seventeenth century onwards one can trace how it intersects with the changing nature of capitalism. Advertising is an institutional method for controlling flows of capital and information; establishing the demands of individuals in order to stabilise an otherwise unpredictable free market; and, beginning in the late nineteenth century, as a way of supporting mass consumption in highly industrialised societies. Advertising, according to Williams, is not as old as human culture, rather, it is functionally tied to the different stages of capitalism. The Italian Neo-Marxists introduced above argue that capitalism has recently undergone a change of state from Fordism to Post-Fordism. Williams' history of advertising, although first published in 1980, was written in 1961 and thus ends before the explosion of information technologies, globalising tendencies, and restructuring of traditional modes of labour that Post-Fordism describes. Extending Williams' history to cover our current moment helps to contextualise Google's model of advertising historically, as well as the way in which it reflects and co-creates our contemporary form of capitalism.

One of the key narratives of advertising, for Williams, is the expansion of its scope, as its function grew to cover an increasing number of commodities and services. As newspapers grew at the end of the seventeenth century so did the number of advertisements, but only for a specific sort of luxury items or medical quackery: '[o]rdinary household goods were rarely advertised; people knew where to get these' (1980, p 172). Modern persuasive advertising, which seeks to establish and perpetuate particular cultural ideals, did not gain dominance until the interwar years of the twentieth-century when it blended with wartime propaganda-posters such as 'Daddy, what did you do in the Great War?' (1980, p 180)-became influenced by advances in modern Psychology, and rode the rising tide of mass media to produce a network of cultural norms that could be bought into through bourgeois products and services. As Williams describes:

'in the 1850s advertising was mainly of a classified kind, in specified parts of the publication. It was still widely felt, in many kinds of trade, that (as a local newspaper summarised the argument in 1859) it is not respectable. Advertising is resorted to for the purposes of introducing inferior articles into the market." (1980, p 173)

It is only in the twentieth-century that advertising became the 'official art of modern capitalist society' (1980, p 184), by which Williams means two things. Firstly, it is the aesthetic that covers the walls of our public places, the insides of newspapers, and funds the employment of a whole creative class. Secondly, it is also 'art' in the sense that it relates to advertising as a 'magic system': a set of practices and cultural myths to perpetuate an unfulfillable materialist desire that serves as an economic engine. To Williams, advertising should be understood as a kind of grammar for a specific historical moment. Given that Google's dominance in online advertising has led to its parent company, Alphabet, to be valued as the second most valuable company on the Fortune 500, with a market value $\$ 579,426$ million (Fortune, 2017), what can Google's mode of advertising tell us about the grammar of contemporary capitalism online?

It is worth noting that the kinds of traditional mass-market advertisements using slogans, celebrities and jingles that play to our 'basic personal relationships and anxieties' (Williams, 1980, p 180) are still with us. Many kinds of advertisements that would not be out of place in the context of twentieth-century television or billboards can be found online, from the pre-roll ads of YouTube to the banner ads underneath the masthead of The New York Times (see Fig. 4). These advertisements that borrow a familiar form have, however, been incorporated into a different model of how media forms function online. This will be outlined in the second half of this article, when our discussion turns to Google's AdSense programme. To understand new forms 
of advertising and their relation to contemporary online capitalism in the light of Williams' historical narrative, we must pause a while longer on Google's dominant form of advertising: AdWords.

As outlined above, the way in which AdWords functions as a 'global real-time and multilingual market' (Kaplan, 2014, p 59) mapping capital directly to specific words and phrases seems at odds with the kinds of advertising that set to establish a generalised demand in a mass market. The algorithmic rating and auction system that selects a particular sponsored link mean that AdWords provides the most relevant advertisement: a listing for an existing demand, rather than a persuasion for something new or different. Google's algorithm, as with its organic results, aims to weed out any misleading, irrelevant or 'inferior articles' (as Williams' 1859 newspaper puts it) and, as outlined above, only charges companies for advertisements when, after Google has selected them as the most relevant, they are actively chosen by users. In addition, the standardised format in which sponsored links are presented cuts out the art of advertising (see, again, Fig. 1). With this outlook, AdWords barely seems like advertising at all. However, these superficial descriptions are not what defines advertising; Google's AdWords functions to structure and control the flow of information and capital in this specific moment of contemporary capitalism. The grammar of digital capitalism is a reflection of Google's structuring of the web. Mass cultural appeal gives way to the long tail of niche commerce; one-way channels of communication and influence become algorithmic feedback loops based around the harvesting of personal data; the growth of immaterial labour expands the reification of previously unmarketable activates into profitable goods and services. AdWords functions as the intermediary form of communication between companies, markets, and individuals that reflects the new grammar of Post-Fordist digital commerce. Google's monopoly on the web is far from an extended caricature of the hegemony of old-media moguls. Although Google dominates, the system is decentred in a number of ways. The most significant of which is that tracing data patterns as a way of mapping 'relevance' draws from the existing behaviours of individuals rather than following any specific normative judgements established by Google. The following section of this article introduces several challenges that demonstrate that although Google dominates the online advertising market, control of capital flows is distributed throughout a complex network of users.

AdWords and the general intellect. The context outlined above demonstrates the ways in which Google draws information from its users to put to economically instrumental ends. It is in this perspective that Matteo Pasquinelli, in an essay specifically focused on Google's PageRank algorithm, describes, 'Google [as] a parasitic apparatus designed to capture the value produced by the common intelligence' (2009, p 155). Pasquinelli describes Google as unproductive: seizing the surplus value of already existing networks and establishing a hegemonic power structure that prevents users from accessing the web without Google's influence. For Pasquinelli, the profits Google makes are part of a wider shift within existing economic and social arrangements, which he describes as 'cognitive capitalism' situating his work within a Post-Fordist framework. In doing so, Pasquinelli draws on the work of Antonio Negri, in particular an essay co-authored with Carlo Vercellone in 2007, in which they argue that rent serves an important function for current modes of cognitive capitalism, as well as Post-Fordism more widely. Pasquinelli paraphrases their argument:

'rent is the central mechanism of the passage from industrial capitalism to cognitive capitalism. In classical economic theory, rent is distinguished from profit. Rent is the parasitic income an owner can earn just by possessing an asset and is traditionally associated with land property. Profit on the other hand, is meant to be productive and is associated with the power of capital to generate and extract a surplus.' (Pasquinelli, 2009, p 158)

Pasquinelli's criticism is primarily focused on PageRank, Google's algorithm that ranks organic search results for each query. For Pasquinelli, the information that PageRank uses is latent in the network and Google's algorithm is simply organising it rather than creating or producing something new. Google's organic rankings are based on existing patterns of hyperlinks on the web and uses these as an indication of sentiment, much like an academic citation system does. So, although a page with numerous hyperlinks pointing to it (or to continue the citation metaphor, a widely-referenced article) might not have been judged as good it is certainly relevant to a particular group of people. Because the main metric of AdWords, relevance, follows the PageRank model, Pasquinelli's argument can be applied to the AdWords mode of advertising. Consequently, as Google's methods of judging relevance are a way of measuring existing behaviours, this information belongs to all users, and as a result, Google is profiting unfairly; in PostFordist terminology, Google is renting users their own judgements. For example, searching for 'Shakespeare' returns a number of high-quality results (see Fig. 3), high-quality in the sense that the results are from reputable sources and pertain to William Shakespeare (of course, judging the results as successful relates to the subjective intentions of a user). However, this hierarchy of quality has not been created by Google; the PageRank algorithm simply reflects the already existing values of web users that have linked to these sites. Pasquinelli's description of Google as global rentier is based on the perspective that although we have Google to thank for providing us access to these sites, the much more significant gratitude must go to the digital community of users for creating this curated list through their collective actions online. Therefore, that Google receives revenue for the usefulness of these results is, from Pasquinelli's perspective, wrong; as the responsibility for the curation and hierarchy lies with the community as a whole: journalists, bloggers, and any kind of user that contributes online. These online participants are not getting paid for their contributions. Instead, users are reimbursed through free access to Google's services, regardless of their level of input. This further demonstrates a characteristic of cognitive capitalism in a wider Post-Fordist context: when users are online they are often unknowingly participating in immaterial labour practices and are collectively remunerated through access to a digital service.

Although Pasquinelli argues that 'Google itself does not produce any content' (2009 p 157), rather it profits from the 'exploitation of a common cognitive space' (2009, p 159), it is important to temper this perspective. Search engine functionality is inherently productive; foregrounding the attitudes of users, through whatever means, is a necessary part of building a robust infrastructure for the web. However, the influence that Google has over the web means that although the web might be a collectively produced space, we have essentially placed its ownership in private hands. The terms of this debate are central to an understanding of Google's role online and while the terminology borrowed from the history of Marxist critique can be helpful, a critique of current technology must be wary of anachronistic deployments that disfigure current forms of capitalism into modes of pre-digital industrial capitalism. 


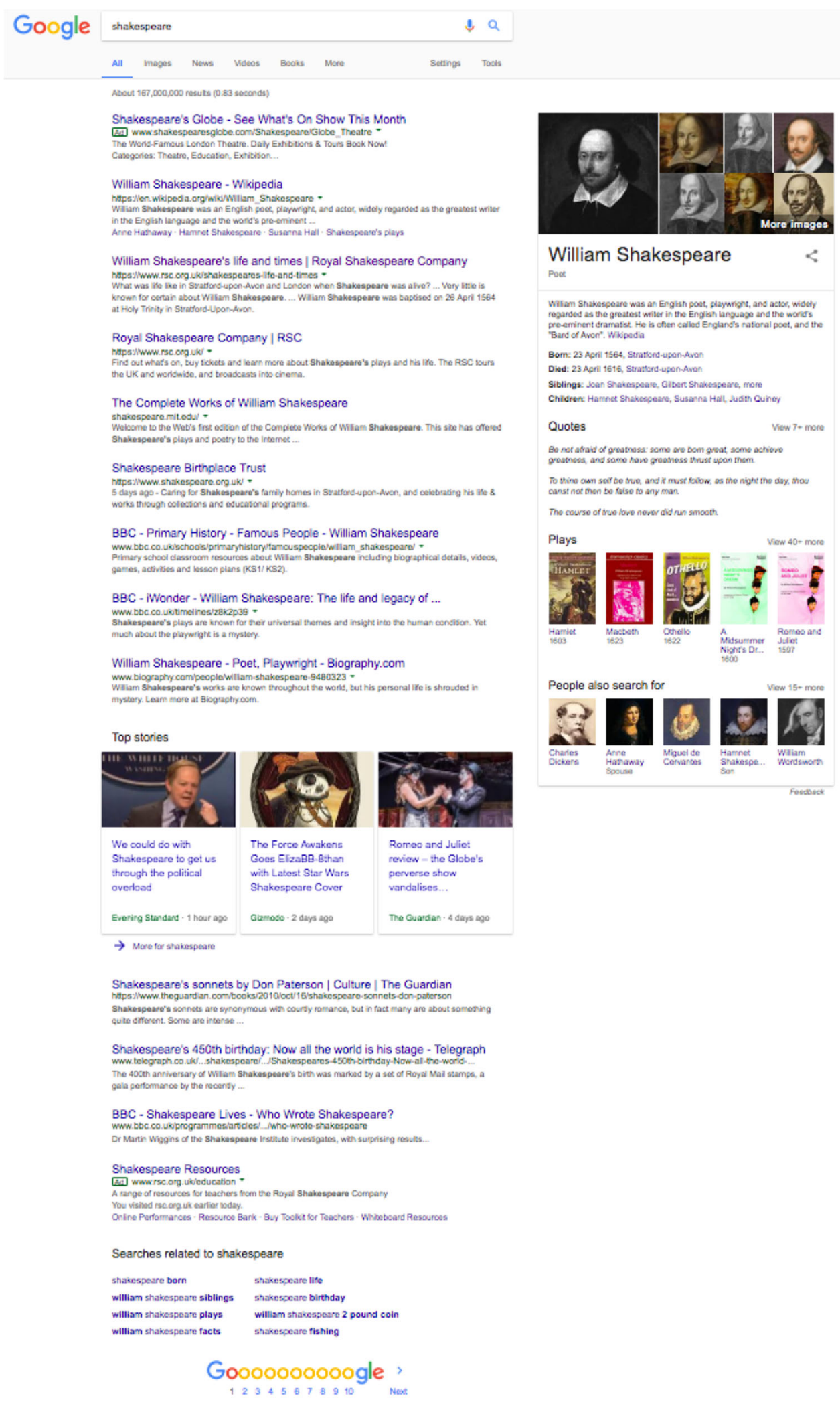

Fig. 3 Google results for 'Shakespeare' an example of high quality results. Screenshot taken by the author. This figure is licensed under a CC-BY Creative Commons Attribution 4.0 International License. Google and the Google logo are registered trademarks of Google Inc., used with permission 
To describe Google's advertising with Post-Fordist terminology we can say that AdWords is a way of functionalising the 'general intellect'. Here, Paolo Virno's reading of this term and his way of updating Marx's original meaning is important:

'Marx, without reserve, equated the general intellect (that is, knowledge as principal productive force) with fixed capital, with the 'objective scientific capacity' inherent in the system of machines. In this way he omitted the dimension, absolutely preeminent today, in which the general intellect presents itself as living labour [...] In the Post-Fordist environment, a decisive role is played by the infinite variety of concepts and logical schemes which cannot ever be set within fixed capital, being inseparable from the reiteration of a plurality of living subjects. The general intellect includes, thus, formal and informal knowledge, imagination, ethical propensities, mindsets, and 'linguistic games'. [...] The general intellect becomes an attribute of living labour when the activity of the latter consists increasingly of linguistic services.' (2004, p 106)

An important feature of the general intellect, as described here, is that it cannot be reduced to simply what a collective has produced, but what it is capable of: the shared 'faculty of thinking; potential as such, not its countless particular realisations' (2004, p 66). As contemporary capitalism continues its trend towards Post-Fordist relations that are underpinned by cognitive or immaterial labour, the general intellect can be functionalised like never before. Google's financial profits are far from the only benefits of the web, but allowing them to be consolidated reduces the collective control of the general intellect, the 'formal and informal knowledge, imagination, ethical propensities, mindsets, and 'linguistic games", that establish and sustain community.

This situation of privately regulated hyperconnection results in what Virno calls 'a publicness without a public sphere' (2004, p 36 ). The web has actualised the previously theoretical connectedness of the multitude, however, the web has not become a democratically shared space, instead it is owned and structured around results that bring economic value and valorise noneconomic ideas. Rather than generalising about the web as one enormous public sphere, it is more accurate to describe the web as a congregation of various multitudes. Each of these publics have different levels of visibility and influence. Importantly, Google AdWords has an uneven coverage of these different multitudes and this has a significant impact on the shape and scope of the web.

Google subdivides users and delivers different results based on a large number of criteria (over 200), such as language, geographical location, and previous search history. The weighting of each criterion changes and is re-established every time a query is searched; it is impossible for users to know which metrics and characteristics influenced their results. Each search causes users to be drawn into a particular multitude, each with its own general intellect and each with its own corresponding sets of search results. The logic of advertising then forces particular criteria to have a disproportionate influence. Jeff Huber, Head of $\mathrm{Ad}$ Engineering at Google, when interviewed by Levy underlined the importance of national space in advertising. Quoted in In the Plex, Huber says:

'[y]es, search is a huge system, but it's stateless-you can easily serve it from ten different places in the world, and if this version is slightly different than that version, the user won't know, nobody will notice. But with advertising, the state is important, because advertisers are always updating their campaigns, and micro transactions are happening at ferocious rates per second, and all that has to be synchronised.' (in Levy, 2011, 116)

Therefore, because of the advertising incentives, a particular metric such as location gains a more significant influence in the kinds of results provided. In addition, the time and effort spent on engineering results follows from economic motivations, prioritising criteria that corresponds to specific users. This leads to a situation in which some languages become more valuable to Google than others. In turn, because some languages have less economic value on the web, the multitudes associated with those languages are accommodated for far less.

There is a lot at stake in debates concerning the ownership of information and good Internet citizenship requires that we stay attentive to Google's role; however, the general intellect, as the current potential for thought, is far more than a collection of specific documents that may or may not be used to extract surplus value. Describing Google as merely parasitic ignores the productive capacities that Google enables by making the web usable. The accessibility of the web that Google's search engine has enabled has allowed for emergent activities and communities that might not exist otherwise. In addition, Google does enable financial remuneration to many online content creators through its second advertising programme, AdSense, the benefits and drawbacks of which are outlined in the second half of this article. Although it is important to observe that these are two separate systems and the beneficiaries of AdSense are by no means the people who contributed to the structure of the web that AdWords profits from. An understanding of AdSense, provided in the latter part of this article, in many ways problematises Pasquinelli's distinction of Google as the global rentier. However, even though AdSense functions very differently than AdWords, an analysis of the two systems provides further evidence as to why Post-Fordist relations are a key lens for understanding Google search and Google as a company.

The future of languages in an incentivised online environment. Before moving on to a discussion of AdSense, which can be described as a way individuals are compensated, or in less generous terms, how particular profitable behaviours are encouraged while others are deincentivised, we must outline a specific consequence of AdWords: its effect on languages. The latent knowledge contained within a language is a key part of the general intellect and a central theme in Post-Fordist descriptions of contemporary capitalism. Virno uses Gilbert Simondon's concept of individuation to describe how a language structures a multitude:

'[1]anguage is pre-individual; it is the historical-natural language shared by all speakers of a certain community. Language belongs to everybody and nobody [...] the use of the spoken word is, at first, something inner-psychic, social, public. A 'private language' does not exist.' (Virno, 2004, p 77)

Each query entered into a search engine is part of this individuating process: an interaction with a wider multitude that through language constructs an individual as a subject. Subjects cannot stand apart from their shared language, as Virno paraphrases Simondon to argue that: individuation is never concluded [...] the subject consists of the permanent interweaving of pre-individual elements and individuated characteristics; moreover, the subject is this interweaving' (Virno, 2004, p 78). It is, therefore, important for the very subjects that are continually emerging that language does not become wholly co-opted by one single economic description. In particular, the reification of AdWords means that the future of a number of languages is at stake, alongside the multitudes that speak with them. 
The lack of diversity of language online is profound. Daniel Prado outlines that: '[b]arely $5 \%$ of the world's languages have a presence in cyberspace' (Prado, 2012, p 34). The decline in language diversity is a general global trend off- and online and Google's impact on the web has followed, if not exacerbated, these general trends. 'The Globalization Group (2010) suggests that $90 \%$ of total international GDP is produced by the speakers of only 14 languages' (2012, p 38). Google has no incentive to provide its services to language groups that do not represent a profitable market. In addition, the populations that are underrepresented on the web often correspond to less economically developed areas, due to the infrastructure and costs required to gain an online presence. Many of these individuals already have a choice between more than one language, as Viola Krebs and Vincent Climent-Ferrando attest in 'Languages, Cyberspace, Migrations': '[i]t is estimated that close to one half of the world's population is bilingual' (2012, p 232). However, the usefulness of a second language online may contribute to a deterioration of a more localised primary language, and the culture that it is tied to. As Prado notes, when communities from less developed countries come online, they choose not to use their native language: '[a] 2003 study by Marcel Diki-Kidiri showed that in a sample of 1374 African sites, only $3.22 \%$ used an African language as the language of communication' (2012, p 39-40). This creates a feedback loop in which, the more that new users find their own language underrepresented, the less likely they are to use it. Therefore, the notion that new web users ever have a choice to start with is radically limited. The web has facilitated the growth of economically useful languages but has prevented a number of languages from ascending to the web. In his 2013 article, Andras Kornai argues that this trend has developed significantly enough to be considered irreparable: the findings of Kornai's team was that 'the vast majority (over 95\%) of languages have already lost the capacity to ascend digitally' (2013, p 2). Languages can disappear online if there is simply one usable alternative. This feedback loop, that limits linguistic diversity, is perpetuated by Google's financial model. The online success of some languages and the failure of others is, in a sense, payment from Google to particular linguistic communities. If users create content in a specific language, Google can harvest its data and enable advertising in that language, which makes searching in that language profitable for Google. If no one is using a language there is no incentive for advertisers to pay Google for specific words and phrases, thus Google accelerates the process of online language death. Therefore, the control over which languages survive is only partially the responsibility of content creators and users; the power is predominately given over to Google.

This process, in which social responsibility is given over to a private company, such as Google, is what Vaidhyanathan describes as 'public failure' (2012, p 6). Google has succeeded in dominating many aspects of people's digital and embodied lives worldwide; many of Alphabets' enterprises make significant losses and are backed up by Google's large advertising revenue; competitors without such a large revenue stream have thus been overtaken or been bought up by Google. Therefore, a discussion regarding Google's financial success is also a discussion of a deal that the global public have made with one company. As Siva Vaidhyanathan puts it:

'[b]ecause of its ease and power, because it does things so cheaply and conveniently, it may cause us to miss opportunities to do things better. Google's presence in certain markets, such as advertising or book search, retards innovation and investment by potential competitors because no one can realistically wrest attention or investment from Google. And when Google does something adequately and relatedly cheaply in the service of the public, public institutions are relieved of the pressure to perform their tasks well. This is an important and troubling phenomenon I call public failure.' (2012, p 6)

In the above quotation, Vaidhyanathan is focused primarily on Google's book scanning project and way in which governments and universities have allowed Google overwhelming control over the future of digital textual content-digitised analog content, as well as born-digital text-because Google covers the costs of investment. Vaidhyanathan's term, 'public failure', is equally applicable in the context of Google's advertising empire. Google is shaping the world we live in by dominating markets through advertising revenue which, in turn, creates more advertising opportunities. Free services, like Google Search, are the payments back to specific multitudes in exchange for using their general intellect for profit. Considering the profits involved, we could argue that the public should be considered as employees of a newly Post-Fordist workforce, creating financially profitable data-sets in their 'spare time', similar to the way that Uber drivers make additional revenue in their 'spare time'. ${ }^{14}$ Also, considering the job losses occurring worldwide (due, in part, to the changing nature of work) this wealth needs to be better shared. However, these arguments have revolved primarily around the taxes that Google, and many other multinational companies, avoid paying. ${ }^{15}$ However, to see Google's profits within a Post-Fordist context, and to describe its users as quasiemployees producing a linguistic landscape for Google to profit from, the payments back to the multitudes should be on a different scale from the current tax systems. Google is not simply making money from the creativity of individuals, but rather shaping all cultural experience on the web into a system that can be easily reified and commodified.

Google's international expansion. A significant part of Alphabet's agenda as a company is to extend their reach and open up the number of contexts in which they can transform into profitable ventures. An example of this is their drive to make as much of offline life machine readable, as mentioned earlier in reference to Google Glass and its related patents. Another kind of expansion that Alphabet has invested in is their drive to provide Internet access across the globe. Google's Project Loon, one of the Alphabet subsidiaries developed using Google's advertising profits, is a 'network of balloons travelling on the edge of space, designed to extend Internet connectivity to people in rural and remote areas worldwide' ('Google: Project Loon'). The project has been described by the company as a kind of social mission, extending the Internet to 4.3 billion people, but in the MIT Technology Review Tom Simonite writes:

'[i]t is odd for a large public company to build out infrastructure aimed at helping the world's poorest people. But in addition to Google's professed desires to help the world, the economics of ad-supported Web businesses give the company other reasons to think big. It's hard to find new customers in Internet markets such as the United States. Getting billions more people online would provide a valuable new supply of eyeballs and personal data for ad targeting. That's one reason Project Loon will have competition: in 2014 Facebook bought a company that makes solar-powered drones so it can start its own airborne Internet project.' (2015)

In this way, it describes another 'public failure' in which a 'blessing' becomes a 'necessary-seemingly natural-part of our daily lives' (Vaidhyanathan, 2012, p 6-7). This provides opportunities for the greater logic of Post-Fordism to enter into 
new rural contexts such as isolated parts of Brazil, Australia, and New Zealand' (Simonite, 2015). Simonite cites Sunil Abraham, executive director of the Centre for Internet and Society, a think tank in Bangalore, writing that, Abraham

is also wary of Project Loon because of the way Google and other Western Internet companies have operated in developing countries in recent years. They have cut deals with telecoms in India and other countries to make it free to access their websites, disadvantaging local competitors. 'Anyone coming with deep pockets and new technology I would welcome,' he says, but he adds that governments should fix up their patchy regulatory regimes first to ensure that everyone-not just Google and its partners-really does benefit.' (quoted in Simonite, 2015).

In the way, not only do the profits of advertising come to underlie the epistemological landscape of the web, but also the infrastructure required for Internet access, offered for free to individuals in developing countries. The potential benefits of opening the Internet up to a wider range of individuals, from different cultures, speaking different languages are multifarious; however, these benefits are not inevitable. If we allow Google, or any other single company, to dictate the physical and digital infrastructure of the web, those multifarious benefits, in order to gain traction, will have to conform to the particular dominant economic affordances of the web. Given the impact of AdWords' reification of language upon linguistic diversity, outlined above, such international expansion may only solidify the current boundaries and limitations of the web. This is not to say that Google's actions are implemented in bad faith, only that the hegemonic situation means that any diversity that is not profitable will struggle and the benefits of widening our online community may well be drastically limited as a consequence. It is in this context, of economic affordances dictating the landscape of the web, that we turn to AdSense, the other side of Google's advertising coin.

AdSense and Post-Fordism. AdSense is the second, smaller, advertising programme that Google operates. AdSense is Google's brokerage programme that enables online content creators to monetise their content by placing third-party adverts on their websites, blogs, or YouTube videos. Sullivan uses the analogy that AdSense 'basically turned the Web into a giant Google billboard. It effectively meant that Google could turn everyone's content into a place for Google ads' (quoted in Auletta, 2011, p 91). AdSense allows users to monetise their online content by setting aside spaces (see Fig. 4 for an example) that Google can fill with adverts that are relevant to the content of the site and/or the user visiting the site. This is accomplished in the following way:

'Google's software crawls the site, performs semantic analysis on the text on each page, and then automatically selects ads that are displayed [...] matched to the meaning of the text. It calls this 'contextual advertising.' Site owners and Google split the proceeds when visitors click on the ads.' (Stross, 2009, p 159)

This process of matching advertisements to content and users has had a large impact on the landscape of the web today, reinforcing associations and shaping what kinds of activities can become profitable. In addition, AdSense as the most dominant online advertising provider has shaped the flows of information and capital in a way that promotes Post-Fordist labour relations between Internet users. There are many benefits to the AdSense model and without it the web would be unrecognisable. However, there are serious negative consequences to a system that values page views, engagements, and shares above all else. This section will cover the impact of AdSense on online discourse and, in particular, analyse the profitability of fake news in the 2016 US presidential election.

AdSense and fake news. It is important to have a clear definition of fake news because it refers to a specific phenomenon that grew in influence during the 2016 US presidential election. Since entering office, President Trump has adopted the phrase, using it against legitimate media organisations, such as CNN, in a way that has muddied the term. Here, the term fake news is used in line with Hunt Allcott and Matthew Gentzkow's definition as 'news articles that are intentionally and verifiably false, and could mislead readers' (2017, p 213). In this way, fake news refers to a specific discourse that proliferated around the presidential election and documented through investigations by BuzzFeed News, The Guardian, and in Allcott and Gentzkow's article 'Social Media and Fake News in the 2016 Election'. Of particular importance is that although the most prominent topic of fake news was-and still is-politics, analysis suggests that these fabricated news stories were written purposely for viral impact and often created purely for profit. Their success can be used to outline some media-specific characteristics of the web and the consequences of structuring the online news environment around advertising revenue. Fake news is not new, nor is it without precedent; Allcott and Gentzkow's article, currently the only academic paper that specifically addresses fake news, provides a multi-disciplinary literature review concerning related phenomena, such as conspiracy theories, as well as a survey of journalistic reports that give examples of individuals who have produced fake news for a number of years. However, the increased proliferation and potential impact of fake news in the 2016 presidential election represents a sea-change, one in which Google's AdSense programme and Google's relationship to the second biggest online advertiser, Facebook, looms large.

Although it is not unusual for the US presidential elections to become an axis around which false claims circulate, the 2016 election saw a different level of misinformation. Articles with inflammatory titles, and which could easily be debunked, such as: 'Pope Francis Shocks World, Endorses Donald Trump for President, Releases Statement', 'Trump Offering Free One-Way Tickets to Africa \& Mexico for Those Who Wanna Leave America', and 'Van Full Of Illegals Shows Up To Vote Clinton At SIX Polling Places, Still Think Voter Fraud Is A Myth?' circulated on social media, in particular on Facebook, at an unprecedented scale. In fact, analysis by BuzzFeed News showed that in 'the final 3 months of the US presidential campaign, the top-performing fake election news stories on Facebook generated more engagement than the top stories from major news outlets such as New York Times, Washington Post, Huffington Post, NBC News, and others' (Silverman, 2016). Although some of the sources that created and disseminated these stories did so for politically motivated reasons, a number of investigations uncovered that the majority of fake news stories were engineered purely to make money from online advertising networks, particularly Google's, and designed without any political motive. It was reported by BuzzFeed and The Guardian that:

'[o]ver the past year, the Macedonian town of Veles (population 45,000) has experienced a digital gold rush as locals launched at least 140 US politics websites. These sites have American-sounding domain names such as WorldPoliticus.com, TrumpVision365.com, USConservativeToday.com, DonaldTrumpNews.co, and USADailyPolitics. com. They almost all publish aggressively pro-Trump content aimed at conservatives and Trump supporters in 


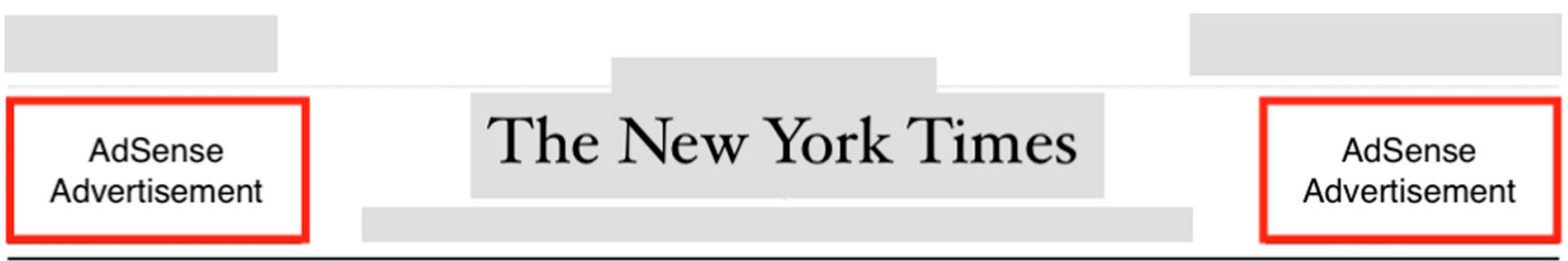

\section{AdSense Advertisement}

Fig. 4 Examples of AdSense banners on the front page of The New York Times website. Screenshot taken by the author. This figure is licensed under a CC-BY Creative Commons Attribution 4.0 International License

the US. [...] The young Macedonians who run these sites say they don't care about Donald Trump [...] These sites open a window into the economic incentives behind producing misinformation specifically for the wealthiest advertising markets and specifically for Facebook, the world's largest social network, as well as within online advertising networks such as Google AdSense.' (Silverman and Alexander, 2016)

Although not all the hyperpartisan, clickbait, and hoax news came from Veles, many news reports also confirmed sources in the US, the geographical and political detachment of those working from Macedonia exemplified the culture of making money through advertising revenue regardless of the content or consequences. Hannah Parkinson's report in the The Guardian described the Veles fake news writers as young people who were simply 'non-partisan kids looking for cash just catering to demand' (2016). Many of the individuals producing fake news about the election had already been earning a good living from advertising revenue of websites aimed at an American audience. Many of the Macedonian creators agreed to be interviewed and it becomes clear that, although a small minority favoured Trump, the subject matter chosen was interchangeable and based around profitable topics. Many of the writers had been creating viral content for years, for example:

'[i]n Veles, Aleksandar and Borce Velkovski are so renowned for the health food website they started that they're known as the Healthy Brothers HealthyFoodHouse. com is a jumble of diet and beauty advice, natural remedies, and other nostrums. It gorges on advertising as it counsels readers to put a bar of soap under their bedsheets to relieve nightly leg cramps or to improve their red-blood-cell count 
with homemade beet syrup. Somehow the website's Facebook page has drawn 2 million followers; more than 10 million unique visitors come to HealthyFoodHouse.com every month.' (Subramanian, 2017)

The creators reinvest part of their earnings to buy fake Facebook profiles and by paying Facebook directly to promote their pages. The analytic feedback tools provided by Facebook and Google allow the creators to develop a good understanding of the criteria that drive content to become viral. Although politically focused content is a recent adaptation, the culture of seeing this kind of activity as a sustainable job had been established for years in Veles. Another creator from Veles, Mirko Ceselkoski, explained in an interview with Samanth Subramanian that he began

in the early 2000s. He built seven or eight websites-about muscle cars or celebrities or superyachts, all oriented toward the American reader, because an American reader is roughly three times more valuable than a non-American one. For five or six hours of daily toil, Ceselkoski says, you can earn approximately $\$ 1000$ a month. Many Macedonians can spare the time; the unemployment rate is around 24 percent.' (2017)

In 2011 Ceselkoski began teaching courses in creating viral media and coaching other individuals, for significant tuition fees, in viral content creation and ways of driving Facebook engagements. Those who took classes from Ceselkoski included the Healthy Brothers as well as individuals responsible for proTrump fake news sites. The previous profits pale in comparison to the success of election fake news '[b]etween August and November, Boris [18-year-old from Veles, real name redacted] earned nearly $\$ 16,000$ off his two pro-Trump websites. The average monthly salary in Macedonia is \$371' (Subramanian, 2017). The nature of this Macedonian cottage industry bears some similarity to various international cyber-crimes, such as the 419 advanced fee scams including the infamous Nigerian prince scam. The fake news writers might not be directly taking money from individuals but they are making money from misleading those in more economically affluent countries. Fake news is not considered criminal in the way that 419 scams are; however, both activities articulate similar characteristics of a globalised online space.

This kind of relationship between individuals and institutions operationalised through international flows of information, labour, and capital exemplifies a Post-Fordist logic outlined at the start of this article. Fabricated stories or not, all creation of online content, whether news or opinion, is a form of precarious employment that foregrounds various aspects of Post-Fordism, many of which lie outside the scope of this article. If this article were to focus directly on the kind of employment of those writing fake news stories, a Post-Fordist lens would highlight the immaterial, flexible, individualised nature of that work. However, it should be clear that the proliferation of fake news impacted and incorporated a much larger group of individuals than simply those writing the stories. By focusing on the wider effects, rather than specifically the niche group of writers, the consequences of online advertising supported content demonstrates a proliferation of Post-Fordist logic, even in the lives of those whose employment is firmly material, industrial, or Fordist.

In particular, the writing, reading and sharing of fake news articles can be seen as components of an immaterial labour arrangement. Immaterial labour is described by Maurizio Lazzarato as:

'the activity that produces the 'cultural content' of the commodity, immaterial labour involves a series of activities that are not normally recognised as 'work'-in other words, the kinds of activities involved in defining and fixing cultural and artistic standards, fashions, tastes, consumer norms, and, more strategically, public opinion.' (2014, p 133)

Immaterial labour is not unique to Post-Fordism, it has served a role stabilising previous economic arrangements, for example, the marketing of cultural values in the twentieth-century that Adorno and Horkheimer refer to as the culture industry. However, the immaterial labour of producing fake news does not shape the values of consumers in order to sell them commodities. Instead, fake news functions by both fixing certain norms and acting as the commodity that matches such a demand; however, such a demand is exacerbated, rather than fulfilled. These norms and values are part of another element of PostFordist labour: affective capitalism. Such a framework highlights the affective qualities of fake news: the reactions it creates as well as the social atmosphere it builds upon. Kylie Jarrett, following the work of Brian Massumi (2002), describes affect as

'those sensory experiences of movement and feeling that are part of the social, cultural and psychological experience of individuals, but which lie beyond the directly signifying properties of discourse. It is differentiated from emotion for it is as an embodied intensity that is outside conscious articulation.' (Jarrett, 2015, p 121)

Here, the similarity to the notion of the 'general intellect' should be noted. Jarrett uses such a perspective within a feminist critique of digital labour in order to argue that it is a mistake to describe individuals online only in terms of rational action. Isto Huvila continues such a call in the context of search engines. Huvila argues that rather than seeing individuals as rational information seekers, what 'counts in the contemporary affective economy of knowing, is the affective attachment to a sensation of being able to know' (Huvila, 2016, p 577). However, although affect must have a significant bearing on the spread of fake news, it is difficult to establish a clear understanding of how and why fake news gained traction, with readers, in the way that it did. Were individuals convinced of the accuracy of the stories or were they shared for other reasons? In taking a large-scale economic focus, this article outlines the economic and advertising-dependent incentives behind the creation and proliferation of fake news, but does not address the smaller-scale actions of individuals, rational or otherwise, on which such a proliferation depends. However, even if nothing is known about their reception, it is the economic structure that provided the informational affordances required for fake news to flourish. It is this economic structure that was jointly reinforced by the way in which Google and Facebook prioritise online content.

The reciprocal relationship between AdSense and Facebook. Although this international aspect of fake news is important, many of the most successful fake news creators reside in the US, for example, Liberty Writers News who were the focus of an interview by The Guardian:

'Liberty Writers News, a two-person site operating out of a house in the San Francisco Bay Area, generates income of between $\$ 10,000$ and $\$ 40,000$ a month from banks of ads that run along the side and bottom of every story. Paris Wade and his partner Ben Goldman have mastered the art of getting traffic. The ability to write a clickbaity headline, toss in some user-generated video found on YouTube, and dash off a 400 -word post in 15 to $30 \mathrm{~min}$ is a skill they don't teach in journalism school, says Wade, who graduated from 


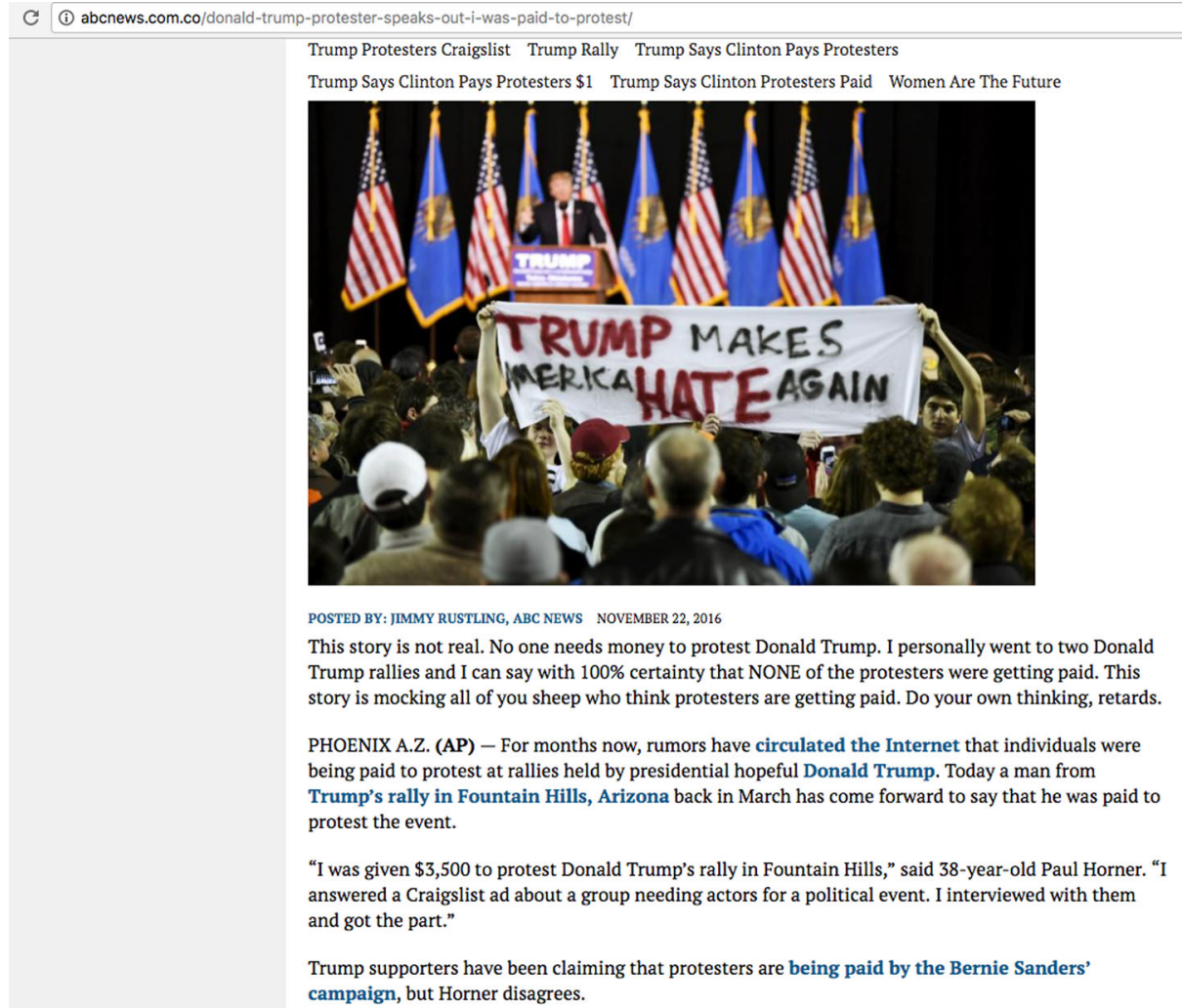

"As for who these people were affiliated with that interviewed me, my guess would be Hillary Clinton's campaign," Horner said. "The actual check I received after I was done with the job was from a group
Guaranteeing Him A Presidential Victory tonygreene 113 on Obama Signs Executive Order: Appoints Rashad Hussain As New Supreme Court Justice

fail on Five things you may have missed over the weekend

John Dread on Donald Trump Protester Speaks Out: "I Was Paid \$3,500 To Protest Trump's Rally" Tyrone on Obama Signs Executive Order Declaring Investigation Into Election Results; Revote Planned For Dec. 19th
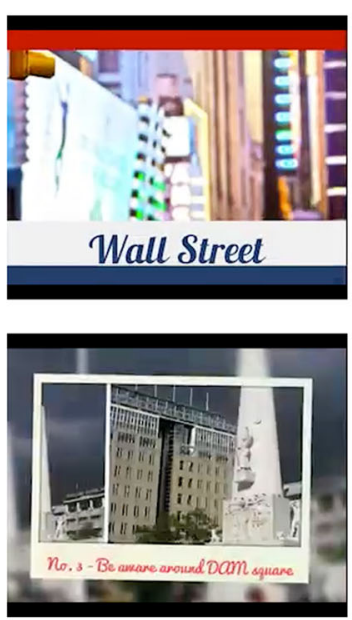

Help The Homeless!!

Fig. 5 Paul Horner's 'Donald Trump Protester Speaks Out: "I Was Paid \$3,500 To Protest Trumps Rally"' article, screenshot as of 8/6/17, including 'This story is not real' paragraph. Screenshot taken by the author. Note: Horner's website was designed to imitate that of the American Broadcasting Company $(A B C)$ News but is not associated with that organisation in any way. The domain abcnews.com.co was shut down as of 3/10/17. An archive of the site can still be viewed using the Internet Archives' waybackmachine. This figure is not covered by a CC- BY Creative Commons Attribution 4.0 International License. This figure is reproduced according to the terms of Fair Use

the University of Tennessee with a degree in advertising.' (Tynan, 2016)

The banks of advertising described were indicated as those provided by AdSense (see SadBotTrue), although interviewees described using multiple platforms. The pair disclose that they 'spend around $\$ 3000$ a month paying Facebook to promote the page' and that '95\% of our [Liberty Writers News] traffic is coming from Facebook'. Here, Facebook benefits in two ways. First, Liberty Writers News pay Facebook directly to promote their site and second, Liberty Writers News urge their readers to 'Share this right now! Let's beat the liberal media to it. Share, share, share it all over Facebook' (Tynan, 2016), which in turn increases the time users spend on Facebook and provides further advertising opportunities. Facebook and Google have little incentive to stop a spread of misinformation as it represents some of the most profitable content on which they host advertisements. In an interview with Bangor Daily News, one US-based fake news creator, Paul Horner, explained his involvement:

'[m]y sites were picked up by Trump supporters all the time. I think Trump is in the White House because of me. His followers don't fact-check anything - they'll post everything, believe anything. His campaign manager posted my story about a protester getting paid $\$ 3500$ as fact. Like, I made that up. I posted a fake ad on Craigslist.' (Quoted in Dewey, 2016)
In addition to Trump's campaign manager, Corey Lewandowski, circulating and promoting Horner's fake news, Caitlin Dewey reports that Eric Trump and Kellyanne Conway also tweeted fake news stories from Horner's site. The original version of the Breitbart article 'Palin on Paid Anti-Trump Protesters: "Not Even President Yet and Our Guy's Already Creating Jobs" (Moons, 2016) cited Horner's fake news story as a source. Horner's fake news site, abcnews.com.co, still hosts the original article 'Donald Trump Protester Speaks Out: "I Was Paid \$3500 To Protest Trump's Rally"' but now starts with an added message that 'this story is not real [...] This story is mocking all of you sheep who think protesters are getting paid' (Horner, 2016) (see Fig. 5). Searching using the Internet Archive's Wayback Machine we can see that this message was not part of the original story (see Fig. 6). Since the results of the election Horner has taken part in numbers of interviews with established news organisations, Channel 4 for example, in which he has promoted himself as someone trying to make the public better informed. In the context of digital capitalism, whether his articles were meant to fuel or satirise Trump supporters is unimportant. Horner, along with many others, has financially benefited from flows of information that are promoted and incentivised by Google AdSense and social media sites such as Facebook.

As far as advertising revenue is concerned, Google has no incentive to care whether these stories are being read as satire by Democrats or sincerely by Republicans. Dewey's article describes how Horner has 'made his living off viral news hoaxes for several years'. In response to a question referring to the announcements 

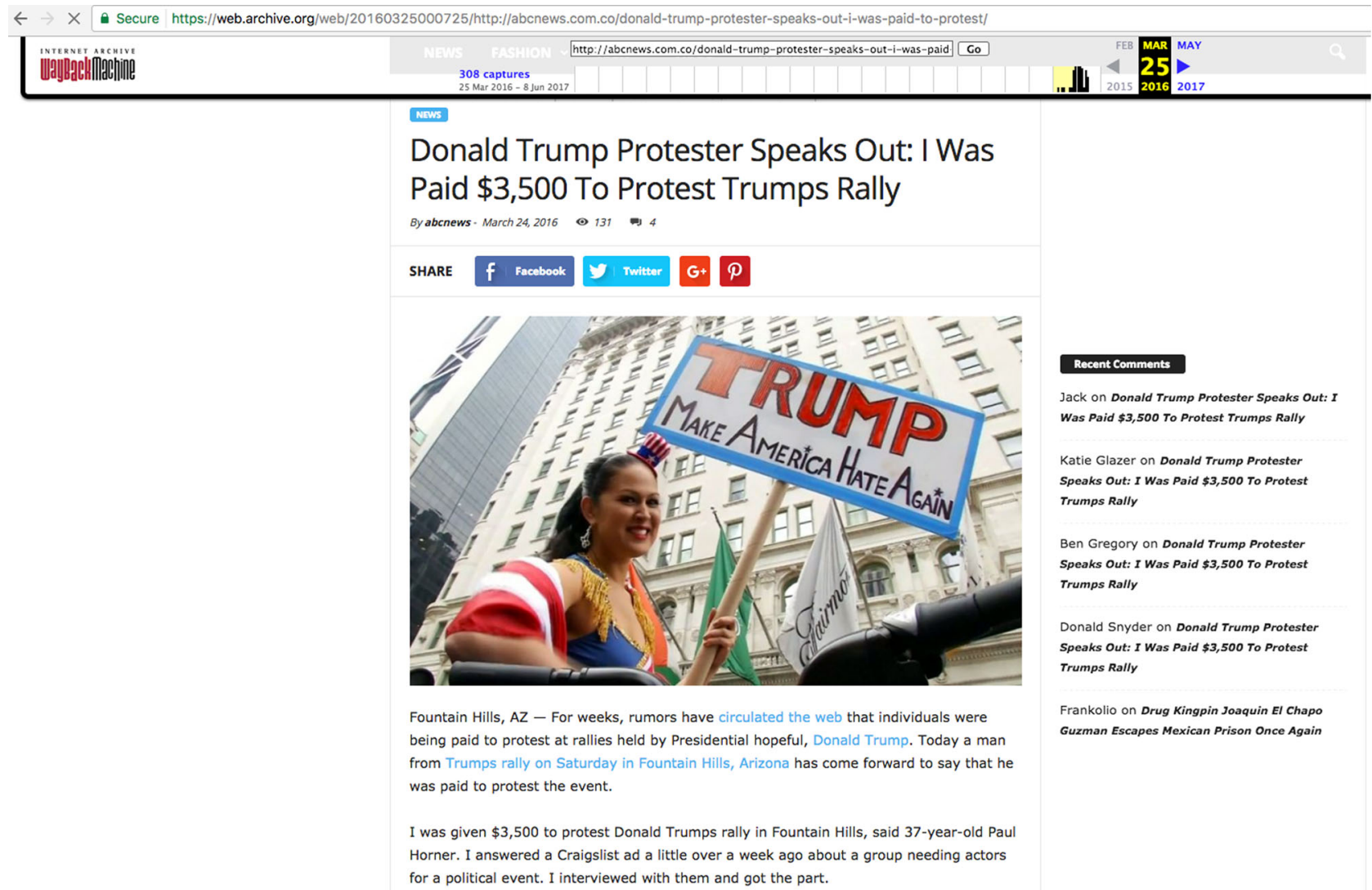

Fig. 6 Paul Horner's 'Donald Trump Protester Speaks Out: "I Was Paid $\$ 3500$ To Protest Trumps Rally"' article, as of 25/3/16 (via waybackmachine), without the 'This story is not real' paragraph. Screenshot taken by the author. Note: Horner's website was designed to imitate that of the American Broadcasting Company ( $A B C$ ) News but is not associated with that organisation in any way. The domain abcnews.com.co was shut down as of $3 / 10 / 17$. An archive of the site can still be viewed using the Internet Archives' waybackmachine. This figure is not covered by a CC- BY Creative Commons Attribution 4.0 International License. This figure is reproduced according to the terms of Fair Use

from Facebook and Google that they would stop allowing fake news sites to use their advertising services, Horner speaks directly to Google's financial incentives to be complicit:

'[r]ight now I make like $\$ 10,000$ a month from AdSense. I know ways of getting hooked up under different names and sites. So probably if they cracked down, I would try different things. I have at least 10 sites right now. If they crack down on a couple, I'll just use others. [...] Plus, Facebook and AdSense make a lot of money from [advertising on fake news sites] for them to just get rid of it. They'd lose a lot of money.' (Dewey, 2016)

Google and Facebook both released statements in midNovember 2016 that they would fight against fake news (Love and Cooke, 2016) by restricting their advertising, with Google claiming the ban would come into effect 'imminently' (Wingfield et al., 2016). However, a number of different reports, including The Wall Street Journal and Media Matters, detailed 'advertisements placed by Google on at least 24 websites that have a track record for pushing fake news stories-stories with fabricated information packaged to appear as a legitimate news story' (Suen et al., 2016). The Media Matters report was conducted on the 12th December, almost a full month after Google stated it would ban fake news sites from their revenue stream on 14th November.

The most popular fake news during the 2016 election favoured Trump over Hillary Clinton. Allcott and Gentzkow collected a database of fake news stories from three major repositories and found that their database contained ' 115 pro-Trump fake stories that were shared on Facebook a total of 30 million times, and 41 pro-Clinton fake stories shared a total of 7.6 million times' (2017, p 212). However, this number does not necessarily mean that all those who were sharing it were Trump supporters. Because so many of the fake news creators aimed to create stories with the largest potential to be widely shared, rather than politically persuade, it may be the case that the most viral stories were those that mobilised online users from across the political spectrum to share the article through outrage, disbelief, agreement or any other motivating factor. Using 'previously reported statistics for the ratio of page visits to shares of stories on social media' Allcott and Gentzkow calculate that the combined ' 38 million shares of fake news in [their] database translates into 760 million instances of a user clicking through and reading a fake news story, or about three stories read per American adult' (2017, p 212). In addition, this figure does not even include users who partially read stories or view headlines within Facebook, Twitter, or Google News directly. These numbers indicate that fake news is not a small issue or one that is easily dismissed. These figures also emphasise the extensive reach that these fake news article had, the accountability of which, also lies with Google and Facebook. Not only did these two companies profit from the surfeit of fake news, but actively promoted it, whether algorithmically or intentionally, through search engine results and social media feeds.

The wider changes in the online access to journalism mean that traditional media outlets now compete for revenue on the same 
terms as fake news sites. Without the institutional stability of print sales ${ }^{16}$ or other regular revenue support, traditional media organisations are drawn into writing in ways that attract attention and generate as many individual page views as possible, in order to increase advertising revenue. Combined with the mediaspecific characteristics of search engine results and social media feeds that decontextualise individual articles and present a diverse range of content, Google and Facebook encourage a logic that incentives clickbait headlines. There is a clear difference between misleading articles and fake news, however, in many ways fake news is a gross exaggeration of current online news practices rather than an activity that occupies a completely separate domain. As long as profits are tied directly to how much an article is shared or viewed then very particular kinds of media content will continue to be incentivised over others.

Fake news is just one example to consider when investigating how Google creates avenues for profit and how Google's economics co-depend on other online institutions, in particular, Facebook. These mutual incentives promote particular kinds of relationships between individual web users and online institutions such as Facebook and Google in a way that promotes Post-Fordist interactions. Immaterial labour is becoming a more expansive domain. As Maurizio Lazzarato argues,

'[i]f production today is directly the production of a social relation, then the 'raw material' of immaterial labour is subjectivity and the 'ideological' environment in which this subjectivity lives and reproduces. The production of subjectivity ceases to be only an instrument of social control (for the reproduction of mercantile relationships) and becomes directly productive, [immaterial workers] satisfy a demand by the consumer and at the same time establish that demand.' (2014, p 143)

The interrelations of Google, Facebook, creators of fake news, and users demonstrate how economic value is being created and harvested from relationships that many online users would not see as primarily economic. These examples also demonstrate how the rise of immaterial labour by no means replaces traditional material labour, but that increasingly the spare time of individuals is spend working, in a Post-Fordist sense, to increase the profits of particular institutions and creators. Even if a user shares a piece of fake news out of outrage, they have still acted within a system that uses advertising revenue to financially compensate its creator, the social media network, and the company that supported its advertising. It is important that web users understand that the web is structured around financial incentives and that, collectively, the actions of following links and sharing pages are intrinsically economic and carry significant consequences for the future of the global information ecology.

\section{Conclusions}

The implications of many of the issues outlined in this article are significant; many of the consequences may seem inescapable or at least difficult to influence. For example, the future of diminishing language diversity appears inevitable, if current economic incentives stay as they are. Nevertheless, this article highlights that there are still potential routes for change. The preceding argument has articulated why Post-Fordist theory provides a useful context for understanding Google's relationship to contemporary digital capitalism. Grounding an understanding of terminology such as immaterial labour and the general intellect can recontextualise current practices and clarify certain intersections of information, capital, and individual agency. When considered alongside Williams' history of advertising, this approach can help us better articulate the current state of capitalism and the particular influence that Google possesses. Describing Google as an advertising company, while appreciating the historically situated nature of this form of advertising, rearticulates the motives behind Alphabet's other projects and underlines how that company is shaping much more than search engine results. Finally, the example of fake news and its expansion during the 2016 US presidential election, although alarming, should serve as an illustration of how online economic incentives produce significant effects that implicate all individuals on a global scale. In summary, this article demonstrates that contemporary digital capitalism is not divorced from the non-digital world, but rather, a significant part of much larger shift within twenty-first century capitalism. Google's influence on this shift is considerable, and therefore, proper Internet citizenship requires that we understand the sway that this particular company holds over current and future digital practices. This understanding is essential if we are to build and sustain a web that reflects the diverse cultures of its global users, rather than the economic incentives of a single company.

Received: 12 June 2017 Accepted: 10 October 2017

Published online: 12 December 2017

\section{Notes}

1 Examples of such disciplinary approaches are as follows: for computer science, see Langville and Meyer (2012); for law, see Vaidhyanathan (2012); for politics, see Ippolita (2013) and Assange (2016); for information retrieval, see Lewandowski (ed.) (2012); for new media studies, see Hillis et al. (2012) and König and Rasch (eds.) (2014).

2 Alphabet has been listed as the world's most valuable company on a number of occasions; see Solomon, 2016a, b.

3 For clarity, this article relies on synecdoche by using 'AdWords' to refer to 'Google properties' and using 'AdSense' to refer to 'Google Network Members' properties'. There are other smaller properties detailed in Alphabet 2016 pages 23 and 24, respectively. However, these smaller properties follow the systems developed by AdWords and AdSense and so, in the main, can be ignored.

4 The collection Radical Thought in Italy: A Potential Politics (ed. Virno and Hardt, 2006) goes some way to providing a comprehensive overview of the important PostFordist theorists, although as is noted in its introduction three key members, Franco Berardi, Sergio Bologna, and Giuseppe Cocco, were not included for various reasons. 5 Fordism emphasises standardisation, de-skilling of the workforce through assemblyline manufacture, and the linking of wages to prices of products in order to ensure that workers could function as consumers of their products. For a more detailed definition and relationship to later forms of capitalism see Amin (1994).

6 See: Google 'AdWords policies'

7 For example, it is illegal to advertise online gambling websites in the USA but legal in the UK and Google follows these geographical distinctions online. See, Google 'AdWord Policies Help: Gambling and Games'

8 For example, the 11 year legal battle between Google Books and The Authors Guild, in which Google's book scanning activities were ruled as legal under fair use, see Cohen, 2015

9 As Anderson explains it, the 'theory of the Long Tail is that our culture and economy is increasingly shifting away from a focus on a relatively small number of 'hits' (mainstream products and markets) at the head of the demand curve and toward a huge number of niches in the tail.' (Anderson)

10 Google encourages this arrangement and details advice for working with a third party, see 'Google: Advertiser guide'

11 See, Racer Nation Information, 2016.

12 See, Google 'Welcome to the 2017 Google Online Marketing Challenge'

13 Various technology commentators have also noted similar data-capture uses for many of Google's acquisitions. For example, Google acquired smart thermostat and smoke detector company Nest in 2013 for $\$ 3.2$ billion. John C. Havens', 2014 article 'The Connected Home May Become the Collected Home' discusses how Google might use these data for personalised advertising purposes.

14 Research has shown that, for most people working in flexible labour roles, this work is not their primary means of income. See, for example, Hall and Krueger, 2015 who show that $51 \%$ of Uber drivers 'drive for less than 15 hours a week, and [...] 85 percent chose to drive less than 35 hours a week.'

15 Google avoids taxes in a number of different ways, including housing profits in Bermuda, to which Eric Schmidt commented 'I am very proud of the structure that 
we set up. We did it based on the incentives that the governments offered us to operate.' See Kavoussi's, 2012 article: 'Google Chairman Eric Schmidt Defends Tax Dodge: "It's Called Capitalism"”

16 A Pew Research study found that between 2005 and 2015 US newspaper 'weekday circulation has fallen $17 \%$ and ad revenue more than 50\%' see Mitchell and Matsa, 2015 .

\section{References}

Alberth JWP (2013) Coupling an electronic skin tattoo to a mobile communication device. Patent number: WO2013166377 A1

Allcott H, Gentzkow M (2017) Social media and fake news in the 2016 election. J Econ Perspect 31:211-236. https://doi.org/10.1257/jep.31.2.211

Alphabet Inc. (2017) Alphabet investor relations: 2016 Annual Report. https://abc.xyz/investor. Accessed 2 Jun 2017

Amin A (1994) Post Fordism: a reader. John Wiley \& Sons, Oxford

Anderson C (no date) The long tail: about me. http://www.longtail.com/about. html. Accessed 4 Jun 2017

Assange J (2016) When Google met WikiLeaks. OR Books, London

Auchard E (2007) Trademark plaintiff drops suit vs. Google over ads. Reuters. http://www.reuters.com/article/us-google-trademark-idUSN033612442007 0904. Accessed 1 Jun 2017

Auletta K (2011) Googled: the end of the world as we know it. Virgin Books, London

Battelle J (2006) The search: how Google and its rivals rewrote the rules of business and transformed our culture. Nicholas Brealey Publishing, London

Berardi F "bifo" (2015) And: phenomenology of the end. MIT Press, South Pasadena, CA

Boutang PYM (2012) Cognitive capitalism. Polity, Cambridge, UK

Brin S, Page L (1998) The anatomy of a large-scale hypertextual web search engine. Presented at the Seventh International World-Wide Web Conference. http:// ilpubs.stanford.edu:8090/361/. Accessed 12 Apr 2017

Cohen D (2015) What the Google books victory means for readers. The Atlantic. https://www.theatlantic.com/technology/archive/2015/10/what-the-googlebooks-victory-means-for-readers-and-libraries/411910/. Accessed 3 Jun 2017

Dewey C (2016) Facebook fake-news writer: "I think Donald Trump is in the White House because of me". The Bangor Daily News. http:// bangordailynews.com/2016/11/17/news/nation/facebook-fake-news-writer-ithink-donald-trump-is-in-the-white-house-because-of-me/ Accessed 1 Jun 2017

Fisher M (2009) Capitalist realism: is there no alternative? Zero Books, Winchester

Fortune (2017) Fortune 500 companies 2017: who made the list. Fortune. http:// fortune.com/fortune500/list/. Accessed 31 May 2017

Globalization Group Inc. (2010) Top languages by GDP. http://www.globalizationgroup.com/edge/2010/03/top-languages-by-gdp/. Accessed 22 Mar 2017

Google (no date) About us: Google. Google. www.google.com/about/. Accessed 14 Feb 2017

Google (no date) Advertiser Guide: working with a third-party partner-Google AdWords. Google. https://www.google.com/intl/en_uk/adwords/thirdparty partners/. Accessed 1 Jun 2017

Google (no date) AdWord policies help: gambling and games. Google. https:// support.google.com/adwordspolicy/answer/6018017?hl=en-GB. Accessed 1 Jun 2017).

Google (no date) Project loon Google. https://x.company/loon/. Accessed 1 Jun 2017 Google (no date) Welcome to the 2017 Google online marketing challenge. Google. https://www.google.com/onlinechallenge/. Accessed 1 Jun 2017

Hall JV, Krueger AB (2015) An analysis of the labor market for Uber's driverpartners in the United States. Working Papers (Princeton University. Industrial Relations Section); 587. http://arks.princeton.edu/ark:/88435/ dsp010z708z67d

Hardt M, Negri A (2001) Empire. Harvard University Press, Cambridge, Mass

Havens JC (2014) The connected home may become the collected home. Slate. http://www.slate.com/blogs/future_tense/2014/07/31/nest_google_acquisition_ the_connected_home_may_be_the_collected_home.html. Accessed 1 May 2017

Heath TB (2012) Advertising based on environmental conditions. Patent Number: US8138930 B1.

Herrman J (2016) Media websites battle faltering ad revenue and traffic. The New York Times. https://www.nytimes.com/2016/04/18/business/media-websitesbattle-falteringad-revenue-and-traffic.html. Accessed 25 May 2017

Hillis K, Petit M, Jarrett K (2012) Google and the culture of search. Routledge, New York

Horner P [pseud. Jimmy Rustling] (2016) Donald Trump protester speaks out: "I Was Paid \$3500 To Protest Trump's Rally”. ABC News. http://abcnews.com. co/donald-trump-protester-speaks-out-i-was-paid-to-protest/. Accessed 8 Jun 2017

Huvila I (2016) Affective capitalism of knowing and the society of search engine. Aslib J Inform Manag 68(5):566-588. https://doi.org/10.1108/AJIM-11-20150178 .
Ippolita (2013) The dark side of Google. Institute of Network Cultures, Amsterdam Jameson F (1992) Postmodernism: or, the cultural logic of late capitalism. Verso Books, London

Jarrett K (2015) Feminism, labour and digital media: the digital housewife. Routledge, New York

Kaplan F (2014) Linguistic capitalism and algorithmic mediation. Representations 127:57-63. https://doi.org/10.1525/rep.2014.127.1.57.

Kavoussi B (2012) 'Google chairman Eric Schmidt defends tax dodge: "It's Called Capitalism"'. Huffington Post. http://www.huffingtonpost.com/2012/12/13/ google-tax-dodge_n_2292077.html. Accessed 18 Apr 2017

König R, Rasch M (eds.) (2014) Society of the query reader: reflections on web search. Institute of Network Cultures, Amsterdam

Kornai A (2013) Digital language death. PLoS One 8:e77056. https:/doi.org/ 10.1371/journal.pone.0077056

Krebs V, Climent-Ferrando V (2012) Languages, cyberspace, migrations. Net. lang: towards a multilingual cyberspace. C\&F éditions, Caen, p 229-248

Langville AN, Meyer CD (2012) Google's Pagerank and beyond: the science of search engine rankings. Princeton University Press, Princeton NJ

Lazzarato M (2014) Signs and machines: capitalism and the production of subjectivity. MIT Press, Los Angeles, CA

Levy S (2011) In the plex: How Google thinks, works, and shapes our lives. Simon \& Schuster, New York

Lewandowski D (ed.) (2012) Web search engine research. Emerald Group Publishing, Bingley

Love J, Cooke K (2016) Google, Facebook move to restrict ads on fake news sites. Reuters. http://uk.reuters.com/article/us-alphabet-advertising-idUKKBN1392 MM. Accessed 4 Mar 2017

Mason P (2016) PostCapitalism: a guide to our future. Penguin, London

Massumi B (2002) Parables for the virtual: movement, affect, sensation. Duke University Press, Durham, NC

Miller CC, Bilton N (2013) How pay-per-gaze advertising could work with Google glass. Bits Blog. https://bits.blogs.nytimes.com/2013/08/20/google-patentsreal-world-pay-per-gaze-advertising/. Accessed 25 Mar 2017

Mitchell A, Matsa K (2015) The declining value of US newspapers. Pew Research Center. http://www.pewresearch.org/fact-tank/2015/05/22/the-decliningvalue-of-u-s-newspapers/. Accessed 2 Jun 2017

Moons M (2016) Palin on paid anti-Trump protesters: "Not Even President Yet and Our Guy's Already Creating Jobs". Breitbart. http://www.breitbart.com/ 2016-presidential-race/2016/07/01/palin-paid-trump-protesters-not-evenpresident-yet-guys-already-creating-jobs/. Accessed 2 Jun 2017

Neven H (2011) Gaze tracking system. Patent number: US20120290401 A1

Parkinson H (2016) Click and elect: how fake news helped Donald Trump win a real election. The Guardian. https://www.theguardian.com/commentisfree/ 2016/nov/14/fake-news-donald-trump-election-alt-right-social-media-techcompanies Accessed 26 Feb 2017

Pasquinelli M (2009) Google's Pagerank algorithm: diagram of cognitive capitalism and the rentier of the common intellect. In: Becker K, Stalder F (eds.) Deep search: the politics of search beyond Google. Studien Verlag, Innsbruck, pp 152-162

Prado D (2012) Language presence in the real world and cyberspace. Net. lang: towards a multilingual cyberspace. C\&F éditions, Caen, p 38-51

Racer Nation Information (2016) MBA students use Google, stukent digital marketing tools. Racer Nation Information. http://www.racernationinformation. com/2016/05/19/mba-students-use-google-stukent-digital-marketing-tools/. Accessed 6 Jun 2017

SadBotTrue (no date) Chapter 39. The fake media. SadBotTrue. http://sadbottrue. com/article/72/. Accessed 1 Jun 2017

Silverman C (2016) This analysis shows how viral fake election news stories outperformed real news on Facebook. BuzzFeed. https://www.buzzfeed.com/ craigsilverman/viral-fake-election-news-outperformed-real-news-onfacebook. Accessed 6 Feb 2017

Silverman C, Alexander L (2016) How teens in the Balkans are duping Trump supporters with fake news. BuzzFeed. https://www.buzzfeed.com/craig silverman/how-macedonia-became-a-global-hub-for-pro-trump-misinfo. Accessed 7 Feb 2017

Simonite T (2015) Google's loon balloons are ready to deliver cheap internet. MIT Technology Review. https://www.technologyreview.com/s/534986/projectloon/. Accessed 27 January 2017

Solomon B (2016a) Google just passed Apple as the world's most valuable company. Forbes. http://www.forbes.com/sites/briansolomon/2016/02/01/google-justpassed-apple-as-the-worlds-most-valuable-company/. Accessed 20 May 2017

Solomon B (2016b) Google passed Apple as the world's most valuable company (again). Forbes. http://www.forbes.com/sites/briansolomon/2016/05/12/ google-passed-apple-as-the-worlds-most-valuable-company-again/. Accessed 20 May 2017

Stross R (2009) Planet Google: how one company is transforming our lives. Atlantic Books, London

Subramanian S (2017) Inside the Macedonian fake-news complex. Wired. https:// www.wired.com/2017/02/veles-macedonia-fake-news/. Accessed 3 May 2017 
Suen B, Holt J, Cherry T (2016) Websites peddling fake news still using Google ads nearly a month after Google announced ban. Media Matters for America. https://www.mediamatters.org/research/2016/12/14/websites-peddling-fakenews-still-using-google-ads-nearly-month-after-google-announced-ban/ 214811. Accessed 18 May 2017

Sullivan D (2016) Google now handles at least 2 trillion searches per year. Search Engine Land. http://searchengineland.com/google-now-handles-2-999trillion-searches-per-year-250247. Accessed 9 May 2017

Truong A (2013) Could Google glass track your emotional response to ads?. Fast Company. https://www.fastcompany.com/3015654/could-google-glass-trackyour-emotional-response-to-ads. Accessed 29 Apr 17

Tynan D (2016) 'How Facebook powers money machines for obscure political "news" sites'. The Guardian. https://www.theguardian.com/technology/2016/ aug/24/facebook-clickbait-political-news-sites-us-election-trump. Accessed 28 Apr 2017

Vaidhyanathan S (2012) The googlization of everything, 2nd updated edition University of California Press, Berkeley, Los Angeles

Virno P (2004) A grammar of the multitude. Semiotext[e], Cambridge, MA

Virno P, Hardt M (eds) (2006) Radical thought in Italy: a potential politics. University of Minnesota Press, Minneapolis, MN

Williams R (1980) Advertising: the magic system. Materialism and culture. Verso Books, London, pp 170-195

Wingfield N, Isaac M, Benner K (2016) Google and Facebook take aim at fake news sites. The New York Times. https://www.nytimes.com/2016/11/15/technology/ google-will-ban-websites-that-host-fake-news-from-using-its-ad-service.html. Accessed 21 Apr 2017

\section{Data availability}

Data sharing is not applicable to this article as no datasets were generated or analysed during the current study.

\section{Acknowledgements}

This research was supported through funding by the Arts and Humanities Research Council [Digital Humanities Doctoral Award (Reference 1099)]

\section{Additional information}

Competing interests: The authors declare no competing financial interests.

Reprints and permission information is available online at http://www.nature.com/ reprints

Publisher's note: Springer Nature remains neutral with regard to jurisdictional claims in published maps and institutional affiliations.

\section{(c) (1)}

Open Access This article is licensed under a Creative Commons Attribution 4.0 International License, which permits use, sharing, adaptation, distribution and reproduction in any medium or format, as long as you give appropriate credit to the original author(s) and the source, provide a link to the Creative Commons license, and indicate if changes were made. The images or other third party material in this article are included in the article's Creative Commons license, unless indicated otherwise in a credit line to the material. If material is not included in the article's Creative Commons license and your intended use is not permitted by statutory regulation or exceeds the permitted use, you will need to obtain permission directly from the copyright holder. To view a copy of this license, visit http://creativecommons.org/ licenses/by/4.0/.

(C) The Author(s) 2017 